\title{
Dichorhaviruses Movement Protein and Nucleoprotein Form a Protein Complex That May Be Required for Virus Spread and Interacts in vivo With Viral Movement-Related Cilevirus Proteins
}

OPEN ACCESS

Edited by:

Nobuhiro Suzuki,

Okayama University, Japan

Reviewed by:

Zhenghe Li,

Zhejiang University, China

Feng Qu,

The Ohio State University,

United States

*Correspondence:

Mikhail Oliveira Leastro

m.leastro@gmail.com

Jesús Ángel Sánchez-Navarro

jesanche@ibmcp.upv.es

Specialty section: This article was submitted to Virology,

a section of the journal

Frontiers in Microbiology

Received: 11 June 2020 Accepted: 06 October 2020

Published: 04 November 2020

Citation:

Leastro MO, Freitas-Astúa J,

Kitajima EW, Pallás V and

Sánchez-Navarro JÁ (2020) Dichorhaviruses Movement Protein and Nucleoprotein Form a Protein

Complex That May Be Required for Virus Spread and Interacts in vivo With Viral Movement-Related Cilevirus Proteins. Front. Microbiol. 11:571807.

doi: 10.3389/fmicb.2020.571807
Mikhail Oliveira Leastro ${ }^{1,2 *}$, Juliana Freitas-Astúa ${ }^{1,3}$, Elliot Watanabe Kitajima ${ }^{4}$, Vicente Pallás ${ }^{2}$ and Jesús Ángel Sánchez-Navarro ${ }^{2 *}$

\footnotetext{
' Unidade Laboratorial de Referência em Biologia Molecular Aplicada, Instituto Biológico, São Paulo, Brazil, ${ }^{2}$ Instituto de Biología Molecular y Celular de Plantas, Universidad Politécnica de Valencia-Consejo Superior de Investigaciones Científicas (CSIC), Valencia, Spain, ${ }^{3}$ Embrapa Mandioca e Fruticultura, Cruz das Almas, Brazil, ${ }^{4}$ Departamento de Fitopatologia e Nematologia, Escola Superior de Agricultura Luiz de Queiroz, Universidade de São Paulo, Piracicaba,
} Brazil

Brevipalpus-transmitted viruses (BTVs) belong to the genera Dichorhavirus and Cilevirus and are the main causal agents of the citrus leprosis $(\mathrm{CL})$ disease. In this report, we explored aspects related to the movement mechanism mediated by dichorhaviruses movement proteins (MPs) and the homologous and heterologous interactions among viral proteins related to the movement of citrus leprosis-associated viruses. The membrane-spanning property and topology analysis of the nucleocapsid $(\mathrm{N})$ and MP proteins from two dichorhaviruses revealed that the MPs are proteins tightly associated with the cell membrane, exposing their $\mathrm{N}$ - and $\mathrm{C}$-termini to the cytoplasm and the inner part of the nucleus, whereas the $\mathrm{N}$ proteins are not membrane-associated. Subcellular localization analysis revealed the presence of dichorhavirus MPs at the cell surface and in the nucleus, while the phosphoproteins (P) were located exclusively in the nucleus and the $\mathrm{N}$ proteins in both the cytoplasm and the nucleus. Co-expression analysis with the MP, $\mathrm{P}$, and $\mathrm{N}$ proteins showed an interaction network formed between them. We highlight the MP capability to partially redistribute the previously reported N-P core complex, redirecting a portion of the $\mathrm{N}$ from the nucleus to the plasmodesmata at the cell periphery, which indicates not only that the MP might guide the intracellular trafficking of the viral infective complex but also that the $\mathrm{N}$ protein may be associated with the cell-to-cell movement mechanism of dichorhaviruses. The movement functionality of these MPs was analyzed by using three movement-defective infectious systems. Also, the MP capacity to generate tubular structures on the protoplast surface by ectopic expression was analyzed. Finally, we evaluated the in vivo protein-protein interaction networks between the dichorhavirus MP and/or $\mathrm{N}$ proteins with the heterologous 
cilevirus movement components, which suggest a broad spectrum of interactions, highlighting those among capsid proteins (CP), MPs, and Ns from citrus leprosisassociated viruses. These data may aid in understanding the mixed infection process naturally observed in the field caused by distinct BTVs.

Keywords: dichorhaviruses, cileviruses, citrus leprosis pathosystem, virus movement, in vivo protein-protein interaction, protein membrane association and topology, mixed infection

\section{INTRODUCTION}

The Brevipalpus-transmitted viruses (BTV) have been separated into two groups: the cytoplasmic type (BTV-C) that replicate in the cytoplasm of infected cells and are composed of viruses of genus Cilevirus, family Kitaviridae (Locali-Fabris et al., 2012; Quito-Avila et al., 2020), and the nuclear type (BTV$\mathrm{N})$, which replicate in the nucleus and are classified in the genus Dichorhavirus, family Rhabdoviridae (Dietzgen et al., 2018; Freitas-Astua et al., 2018). BTV from both genera are causal agents of citrus leprosis (CL), a re-emergent viral disease characterized by the induction of localized chlorotic and necrotic lesions on infected citrus tissues, which affects the crops from South to North America (Bastianel et al., 2010) and was recently identified in South Africa (Cook et al., 2019). Dichorhaviruses share molecular and biological characteristics with non-segmented plant rhabdoviruses that replicate in the nuclei, such as the sonchus yellow net virus (SYNV) and datura yellow vein virus (DYVV) (Dietzgen et al., 2018). In 2019, the International Committee on Virus Taxonomy (ICTV) split the former genus Nucleorhabdovirus into three new genera Alphanucleorhabdovirus, Betanucleorhabdovirus, and Gammanucleorhabdovirus (Freitas-Astúa et al., 2019; Dietzgen et al., 2020). This decision was based on the observation that the betanucleorhabdoviruses, like SYNV and DYVV, cluster together as sister clades with the dichorhaviruses (Freitas-Astúa et al., 2019; Dietzgen et al., 2020). Orchid fleck virus (OFV) is the type member of the genus Dichorhavirus and the only BTV that has a worldwide distribution. It was firstly identified in orchid plants in Japan (Kondo et al., 2003) and, in addition to Asia, occurs in the Americas (Freitas-Astúa et al., 2002), Europe (Petzold, 1971; Sauvetre et al., 2018), Oceania (Gibbs et al., 2000), and it was recently detected in the African continent (Cook et al., 2019). A citrus strain of OFV (OFV-citrus) has been found infecting several citrus genotypes in Mexico, Colombia, and South Africa causing CL symptoms (Cruz-Jaramillo et al., 2014; Roy et al., 2015b; Cook et al., 2019). More recently, citrus leprosis virus $\mathrm{N}(\mathrm{CiLV}-\mathrm{N})$ and citrus chlorotic spot virus (CiCSV), two new dichorhaviruses also associated with CL disease, were identified in citrus plants in Brazil (RamosGonzalez et al., 2017; Chabi-Jesus et al., 2018). Citrus leprosis is indeed an unusual disease, caused by viruses belonging to two completely distinct genera but sharing some similarities as the particle morphology, symptomatology in citrus plants, and the Brevipalpus spp. mite vector. Not only different species of viruses but also of Brevipalpus can be found in citrus orchards associated with CL (Sanchez-Velazquez et al., 2015; Beltran-Beltran et al., 2020). In this context, mixed infections with the cilevirus citrus leprosis virus C2 (CiLV-C2) and the dichorhavirus OFV-citrus infecting the same leaf lesion were recently identified in Citrus sinensis (sweet orange) in Colombia (Roy et al., 2015a).

Dichorhaviruses contain (-)ssRNA bisegmented genomes (Dietzgen et al., 2018). RNA 1 codes for the nucleocapsid protein $(\mathrm{N})$, phosphoprotein $(\mathrm{P})$, putative movement protein (MP), matrix protein (M), and glycoprotein $(\mathrm{G})$, while RNA2 codes for the L protein, an RNA-dependent RNA polymerase (RdRp) (Kondo et al., 2014; Dietzgen et al., 2018; Freitas-Astua et al., 2018). The protein-protein interaction and subcellular map localization of the dichorhaviruses proteins in the plant cell have been explored. A recent study showed the nucleophilic properties of five coffee ring spot virus (CoRSV) proteins and their capacity to interact with each other (Ramalho et al., 2014). The MP is distributed along the cell periphery, and it is the only protein unable to interact with other CoRSV proteins. The $\mathrm{P}$ protein is observed exclusively into the nuclei, while the $\mathrm{N}$ protein is observed both in the nucleus and in the cytoplasm. The P is relocalized to the cytoplasm when co-expressed with the $\mathrm{N}$, suggesting that the $\mathrm{N}$ could mediate the intracellular transport of infectious viral components from the nucleus to the cell periphery (Ramalho et al., 2014). In a more detailed study aiming to unravel the mechanism of OFV nuclear viroplasm formation, it was shown that $\mathrm{N}$ accumulates throughout the cell and $\mathrm{P}$ is associated with the cell nuclei, with the $\mathrm{N}$ being recruited to the nuclei by the presence of $\mathrm{P}$, forming a intranuclear viroplasmlike structure mediated by $\mathrm{P}$ nuclear localization signal (NLS) (Kondo et al., 2013). In contrast, for SYNV, the genetically related betanucleorhabdovirus, both $\mathrm{N}$ and $\mathrm{P}$ proteins are separately imported into the nucleus via NLS-dependent and -independent pathway systems, respectively (Goodin et al., 2001; Deng et al., 2007; Kondo et al., 2013). Although the nuclear importing activity for dichorhavirus nucleocapsids is relatively well resolved, the mechanism as to how the core ribonucleoprotein (RNP) complex is exported from the nucleus to the plasmodesmata for cell-tocell movement, with special emphasis on MP's participation, still needs elucidation.

To establish systemic infection in plants, viruses have evolved genes that encode specialized proteins essential for their transport. These MPs act in synchronization with viral and host factors resulting in sophisticated movement strategies in order to ensure effective viral spread. The MPs could facilitate the intracellular virus spread from the viral sites of replication to cell periphery, then to neighboring cells through structural changes in the plant intracellular connections, the plasmodesmata (PD). Once the MP reaches the PD connection, this protein may assist the virus transport to neighboring cells in different ways: (i) as a viral vRNP complex, (ii) as a viral replication complex (VRC), 
(iii) as virions through a tubule-mediated mechanism, or (iv) by an intermediate mechanism, where tubular structures promote the movement of ribonucleoprotein complexes which include the coat protein rather than the entire particle (Sanchez-Navarro and Bol, 2001; Kawakami et al., 2004; Sanchez-Navarro et al., 2006; Ritzenthaler and Hofmann, 2007; Hofmann et al., 2009; Sambade and Heinlein, 2009; Navarro et al., 2019). Furthermore, some MPs might require their cognate nucleocapsid proteins in some steps of the movement process to allow viral transport (Nagano et al., 1997; Sanchez-Navarro and Bol, 2001; Sanchez-Navarro et al., 2006; Aparicio et al., 2010).

As reviewed by Leastro et al. (2015), interactions among viruses seem to be a common feature in nature. Mixed infection under natural conditions between viral species of the same or related genera may provide greater genetic diversity favoring virus infection, genetic reassortment and recombination (Brown et al., 2002; Idris and Brown, 2004; Idris et al., 2008; Leastro et al., 2015). A more extensive study on the interaction among viral proteins of members of the same or between related genera associated with the CL disease may shed light on the nature of mixed plant infection and mite colonization by both BVT-N and BTV-C. In this scenario, we selected to study the dichorhavirus MP, N, and P, and the cilevirus p32 (MP) and p29 (capsid) proteins, which are putatively associated with their movement mechanisms (Leastro et al., unpublished). Therefore, they have potential to be critical components of compatibility in the natural mixed infection process observed in the $\mathrm{CL}$ pathosystem. For that, we first evaluated the interaction complex formed among MP, N, and P of the dichorhaviruses CiLV-N and OFV-citrus, focusing on the mechanism of action of the MP to ensure viral movement. Then, we explored the association between dichorhavirus movement components with the key viral components associated with the movement of cileviruses, so a comprehensive discussion was generated in order to better understand the process of mixed infection between members of viral species of two distinct genera.

\section{MATERIALS AND METHODS}

\section{DNA Manipulation}

$M P, N$, and $P$ genes of CiLV-N (isolate Ibil GenBank access: KX982176.1) and OFV-citrus (isolate M2345 GenBank access: KF209275.2) were obtained from total RNA extracted from infected citrus samples. RT-PCR was performed following the manufacturer's specifications (Thermo Fisher Scientific, United States). The cDNA was generated with specific primers for each gene, followed by PCR amplification with the primers carrying the sites NcoI/NheI (N CiLV-N), BspHI/NheI ( $P$ CiLV-N and $M P$ OFV-citrus), $P$ ciI/NheI (MP CiLV-N and $P$ OFV-citrus), and $\mathrm{NcoI} / \mathrm{XbaI}$ (N OFV-citrus).

For the analysis of cell-to-cell spread, a modified infectious alfalfa mosaic virus (AMV) cDNA 3 clone (pGFP/A255/CP) (Sanchez-Navarro et al., 2001), which expresses the green fluorescent protein (GFP), was used to exchange the 255 amino acids (aa) of the AMV MP gene with the corresponding putative $M P, N$, and $P$ of CiLV-N or OFV-citrus. The genes were cloned with the compatible sites NcoI/NheI. The resultant constructs carrying the heterologous indicated proteins were fused with the C-terminal 44 aa (A44) of the AMV MP, which favors a better efficiency in movement, given that this region is responsible for the interaction to the cognate AMV capsid protein (CP) (Sanchez-Navarro et al., 2006; Aparicio et al., 2010). In addition, the $M P, N$ and $P$ genes containing stop codon sequences were introduced into the AMV cDNA 3 clone to generate proteins not fused with A44.

For turnip crinkle virus (TCV) assay of in trans movement complementation, the dichorhavirus MPs carrying stop codons were introduced in the expression cassette of the plasmid pSK35S-MP ${ }_{\mathrm{TSWV}}$ :HA-PoPit by replacing the TSWV NSm gene (Leastro et al., 2017a). The expression cassettes containing CiLV$\mathrm{N}$ or OFV-citrus $M P$ were subcloned into the $\mathrm{pMOG}_{800}$ binary vector by using the restriction site HindIII.

To evaluate the subcellular localization and redistribution of the proteins, the enhanced GFP (eGFP) gene was fused at the Cor N-termini of the different viral genes. For C-terminal fusion, the genes were cloned into the vector pSK35S-GFP:eGFP-PoPit (Leastro et al., 2015) replacing the GFP gene. For the protein relocalization assay, the CiLV-N and OFV-citrus $P$ genes were fused at their C-termini with RFP (red fluorescent protein) using the plasmid pSK35S-GFP:RFP-PoPit. The resultant clones contained the corresponding dichorhaviruses genes fused to the eGFP or RFP, or non-fused, under the control of $35 \mathrm{~S}$ constitutive promoter from cauliflower mosaic virus (CaMV) and the terminator from the potato proteinase inhibitor (PoPit) (Leastro et al., 2015). The correspondent expression cassettes were subcloned into the pMOG $_{800}$ binary vector by using the restriction sites EcoRI/XhoI or HindIII. For the $\mathrm{N}$ termini fusions, the genes were inserted into the vector pSK 35S-eGFP:GFP-PoPit replacing the GFP and subcloned into the $\mathrm{pMOG}_{800}$ binary vector as above mentioned.

For the membrane association or tubule formation assays, the $M P, N$, and $P$ dichorhaviruses proteins were human influenza hemagglutinin (HA)-tagged at their C-termini by insertion into the pSK35S-MP $P_{\mathrm{CiLV}-\mathrm{C}}: \mathrm{HA}-\mathrm{PoPit}$ construct (Leastro et al., 2018), replacing the citrus leprosis virus $\mathrm{C}(\mathrm{CiLV}-\mathrm{C}) M P$ gene. Then, the expression cassettes were subcloned into the $\mathrm{pMOG}_{800}$ binary vector by using the restriction site HindIII.

For the BiFC analyses, membrane topology, and in vivo viral protein-protein interaction, we inserted the viral genes in the constructs pSK35S-NYFP:eGFP-PoPit, pSK35S-CYFP:eGFP-PoPit, pSK35S-eGFP:NYFP-PoPit, and pSK35S-eGFP:CYFP-PoPit, which permitted N-and C-terminal fusion of the enhanced yellow fluorescent protein (EYFP) fragments at the $\mathrm{N}$ - or C-termini of a specific assayed protein by exchange of the eGFP gene using the NcoI/NheI restriction sites. Detailed procedures for obtaining these plasmids were previously described (Leastro et al., 2015). In short, we fused the N-terminal 154 amino acids of the YFP (NYFP) to the $\mathrm{N}$ - and C-termini of the $M P, N$, and $P$ dichorhaviruses proteins. The C-terminal 84 amino acids of the YFP (CYFP) were also fused to the $\mathrm{N}$ - or C-termini of the mentioned proteins. The cassettes containing the corresponding genes were subcloned into the $\mathrm{pMOG}_{800}$ binary vector as aforementioned. 
The constructs, which contained the $\mathrm{N}$ - and C-termini fragments of the EYFP addressed to the cytosol (NYFPcyt and CYFPcyt) or ER (NYFPer and CYFPer) used here for BiFC topology, were obtained from Aparicio et al. (2006) and Zamyatnin et al. (2006), respectively.

The BiFC, HA-tagged and non-fused constructs carrying the p29 and/or MP genes of the cileviruses CiLV-C and CiLV-C2 were obtained from Leastro et al. (2018) and Leastro et al. (submitted). All constructs and DNA manipulation steps were confirmed by plasmid DNA sequencing.

\section{Subcellular Fractionation, Chemical Treatment, and Western Blot Analyses}

Agrobacterium tumefaciens strain C58 cultures were transformed with binary $\mathrm{pMOG}_{800}$ plasmid, harboring the dichorhavirus $M P$ and $N$ genes and leader peptidase (Lep) gene fused at their C-termini to the HA epitope. The Lep construct was obtained from Peiro et al. (2014b). The pUC35s-GFP-HDEL plasmid that expresses free GFP with ER retention signal was introduced by electroporation into the Agrobacterium strain GV3101. The cultures $\left(\mathrm{OD}_{600}\right.$ 0.4) were individually agroinfiltrated in Nicotiana benthamiana leaves as described previously (Leastro et al., 2015). After 3 days post infiltration (dpi), the leaves were processed to obtain enriched membranous fraction. As previously related by Leastro et al. (2018), approximately $1.5 \mathrm{~g}$ of infiltrated leaves were ground in lysis buffer [20 mM HEPES, $\mathrm{pH} 6.8 ; 150 \mathrm{mM}$ potassium acetate; $250 \mathrm{mM}$ mannitol; $1 \mathrm{mM}$ $\mathrm{MgCl}_{2}$ and $50 \mu \mathrm{L}$ of protease inhibitor cocktail for plant cell (Sigma-Aldrich, Steinheim, Germany)]. The homogenate was clarified by centrifugation at $3,000 \times g$ for $10 \mathrm{~min}$ at $4^{\circ} \mathrm{C}$. The collected supernatant was ultracentrifuged at $40,000 \times g$ for $40 \mathrm{~min}$ at $4^{\circ} \mathrm{C}$ to yield the soluble (S30) and the crude (P30) microsomal fractions. Microsomal pellets were resuspended in lysis buffer and divided into five fractions, to which the same volume of original lysis buffer (control aliquot); $100 \mathrm{mM}$ $\mathrm{Na}_{2} \mathrm{CO}_{3}$ ( $\mathrm{pH} 11.0$ ); and $2 \mathrm{M}, 4 \mathrm{M}$, and $8 \mathrm{M}$ urea were added and incubated for $30 \mathrm{~min}$ on ice. The supernatant fractions (S30) were collected by ultracentrifugation at $40,000 \times g$ for $40 \mathrm{~min}$ at $4^{\circ} \mathrm{C}$ and the respective pellets (P30) were resuspended in the same volume with lysis buffer. Treatment of the pellet (P30) with Triton X-114 was performed separately. As referred by Kang et al. (2015), the P30 fraction was resuspended in the lysis buffer containing 1\% Triton X-114 followed by incubation on ice for $30 \mathrm{~min}$. Mixture was clarified by centrifugation at $10,000 \times g$ for $20 \mathrm{~min}$ at $4^{\circ} \mathrm{C}$, then the supernatant was incubated at $37^{\circ} \mathrm{C}$ for $10 \mathrm{~min}$ at room temperature to form the aqueous (AP) and the hydrophobic phase (OP), and centrifuged at $10,000 \times \mathrm{g}$ for $10 \mathrm{~min}$ at room temperature for phase separation. Finally, the OP was resuspended in lysis buffer with the same volume obtained in the aqueous phase. All the fractions were analyzed by Western blot in $12 \%$ SDSPAGE gels. The gels were electrotransferred to polyvinylidene difluoride membranes following the manufacturer's instructions (Amersham $^{\text {TM }}$ Protan $^{\circledR}$, GE Healthcare, United States). The detection of the proteins tagged with HA or the GFP and percentage values of relative concentration of the protein gel bands was performed as described previously (Leastro et al., 2015).

\section{Intracellular Protein Sublocalization and Redistribution}

To visualize the intracellular localization of dichorhavirus MP, N, and $\mathrm{P}$ proteins in plant cells, A. tumefaciens cultures containing the viral genes fused to the eGFP, RFP, or HA tag in $\mathrm{pMOG}_{800}$ binary vector were infiltrated in $N$. benthamiana leaves $\left(\mathrm{OD}_{600}\right.$ 0.4 ) as described before. The plants were kept at $23^{\circ} \mathrm{C}$ in the light for $16 \mathrm{~h}$ and at $18^{\circ} \mathrm{C}$ in the dark for $8 \mathrm{~h}$ with $70 \%$ relative humidity. The fluorescence was observed between 48 and $72 \mathrm{~h}$ post-infiltration.

To investigate the colocalization of the dichorhaviruses proteins with the nucleus or the redistribution of the proteins, simultaneous expression of two or three proteins in individual bacteria cultures containing the correspondent binary vectors carrying the dichorhavirus genes or the organelle markers was performed. For all subcellular expression analyses, three independent experiments were performed, each one included the infiltration of three leaves per construct such as performed by Leastro et al. (2018). All images displayed are representative of at least three independent experiments.

\section{Organelle Markers}

For the nucleus subcellular colocalization, the proteins were co-infiltrated with cultures $\left(\mathrm{OD}_{600} 0.1\right)$ expressing the nuclear localization signal of SV40 large T antigen fused to the RFP, kindly provided by Dr. José Navarro IBMCP, Valencia, Spain.

As described by Leastro et al. (2018) for callose staining, $N$. benthamiana leaves were infiltrated with aniline blue (Merck KGaA, Darmstadt, Germany) solution at $0.005 \%$ concentration in sodium phosphate buffer, $70 \mathrm{mM}, \mathrm{pH}$ 9.0. The leaves were infiltrated and kept in a dark room for $2 \mathrm{~h}$ before confocal visualization.

\section{Bimolecular Fluorescence Complementation Assays}

All procedures for the BiFC assays were conducted as previously reported by Leastro et al. (2018). In short, A. tumefaciens (strain C58) cultures $\left(\mathrm{OD}_{600}\right.$ 0.4) transformed with the corresponding binary plasmid $\mathrm{pMOG}_{800}$ were used to infiltrate $N$. benthamiana plants as previously mentioned. At $4 \mathrm{dpi}$, the fluorescence reconstitution was observed. To increase the expression, in order to allow a better visualization of the fluorescence signal, all protein pair combinations were co-expressed with the silencing suppressor HCPro from tobacco etch virus.

For the BiFC assay aiming to characterize the topology of $\mathrm{N}$ and MP dichorhavirus proteins, the $\mathrm{N}$ and MP carrying the NYFP or CYFP fused at their N- or C-termini were transiently expressed with the counterpart addressed to the cytosol (N-YFPcyt and C-YFPcyt) or ER lumen (C-YFRer and N-YFPer) (Leastro et al., 2018). All protein pair combinations performed in the BiFC topology analyses are shown in Table 1.

For in vivo protein-protein interaction, the dichorhaviruses $(\mathrm{N}, \mathrm{P}$, and MP) and cileviruses (p29 and MP) proteins were 
TABLE 1 | Protein pair combinations performed in the BiFC topology assay for MPs and Ns proteins of the CiLV-N and OFV-citrus.

\begin{tabular}{|c|c|c|c|c|c|}
\hline \multicolumn{2}{|c|}{ Membrane topology } & \multirow[t]{2}{*}{ NYFP-Cyt } & \multirow{2}{*}{$\begin{array}{c}\text { CYFP-Cyt } \\
-\end{array}$} & \multirow[t]{2}{*}{ NYFP-ER } & \multirow{2}{*}{$\begin{array}{c}\text { CYFP-ER } \\
+\end{array}$} \\
\hline Control & NYFP-ER & & & & \\
\hline & NYFP-Cyt & & + & & - \\
\hline \multirow[t]{8}{*}{ CiLV-N } & N-NYFP & & + & & - \\
\hline & N-CtYFP & - & & - & \\
\hline & NYFP-N & & + & & - \\
\hline & CYFP-N & - & & - & \\
\hline & MP-NYFP & & + & & - \\
\hline & MP-CYFP & - & & - & \\
\hline & NYFP-MP & & + & & - \\
\hline & CYFP-MP & - & & - & \\
\hline \multirow[t]{8}{*}{ OFV-citrus } & N-NYFP & & + & & - \\
\hline & N-CYFP & - & & - & \\
\hline & NYFP-N & & + & & - \\
\hline & CYFP-N & - & & - & \\
\hline & MP-NYFP & & + & & - \\
\hline & MP-CYFP & - & & - & \\
\hline & NYFP-MP & & + & & - \\
\hline & CYFP-MP & - & & - & \\
\hline
\end{tabular}

The symbols - and + correspond to the absence and presence of fluorescence signals, respectively. NYFP and CYFP correspond to half $\mathrm{N}$ - and C-terminal of the YFP protein, respectively.

fused at their $\mathrm{N}$ - and C- termini with NYFP and CYFP. In dimerization analysis, performed individually for each dichorhavirus or cilevirus protein, the indicated pair of proteins was transiently expressed in $N$. benthamiana as described previously by Leastro et al. (2018). The same was performed in the heterologous associations; however, the combination pairs were performed between different proteins from the same species (intra-association) or different species of the same genus (inter-association), or also between species of different genera (inter-association between genera). Tables 2, 3 summarize all combinations performed in dimerization and heterodimerization assays, respectively. For BiFC analyses, three independent experiments were performed, each one included the infiltration of three leaves per construct. All BiFC images displayed are representative of at least three independent experiments.

\section{Confocal Laser Scanning Microscopy}

Fluorescence images of the leaf discs from $N$. benthamiana were captured with the aid of a confocal laser scanning microscope Zeiss LSM 780 model. Aniline blue fluorochrome was excited at $405 \mathrm{~nm}$, and emission was captured at 410-480 nm. GFP fusion proteins were excited at $488 \mathrm{~nm}$ and emission was captured at 495-520 nm. YFP was excited at $514 \mathrm{~nm}$ and emission was captured at 520-560 $\mathrm{nm}$. The mRFP fluorophore was excited at $552 \mathrm{~nm}$ and emission was captured at 585-610 nm. The images were prepared using Fiji ImageJ program (version 2.0r).

\section{Protoplast Preparation}

$N$. benthamiana leaves (three per each construct) were individually infiltrated with $A$. tumefaciens (strain C58)
TABLE 2 | Protein pair combinations performed in the BiFC dimerization assay.

\begin{tabular}{|c|c|c|c|c|c|c|}
\hline \multirow[t]{2}{*}{ Dimers } & \multicolumn{3}{|c|}{ CiLV-N } & \multicolumn{3}{|c|}{ OFV-citrus } \\
\hline & $\mathbf{N}$ & MP & $\mathbf{P}$ & $\mathbf{N}$ & MP & $\mathbf{P}$ \\
\hline ORF-NYFP + ORF-CYFP & - & - & + & + & + & + \\
\hline ORF-NYFP + CYFP-ORF & + & - & + & + & - & + \\
\hline NYFP-ORF + ORF-CYFP & - & + & + & - & - & + \\
\hline NYFP-ORF + CYFP-ORF & + & + & + & + & - & + \\
\hline \multicolumn{7}{|l|}{ Negative controls } \\
\hline CYFP-ORF + NYFP-Cyt & - & - & - & - & - & - \\
\hline ORF-CYFP + NYFP-Cyt & - & - & - & - & - & - \\
\hline NYFP-ORF + CYFP-ER & - & - & - & - & - & - \\
\hline
\end{tabular}

The symbols - and + correspond to the absence and presence of fluorescence signals, respectively. NYFP and CYFP correspond to half $\mathrm{N}$ - and C-terminal of the YFP protein, respectively.

cultures $\left(\mathrm{OD}_{600}\right.$ 0.5) transformed with the corresponding binary vector pMOG $_{800}$ containing the dichorhavirus MPs or co-infiltrated in combination with the N-HA, P-HA, and N-HA $+P$-HA. The infiltrated leaves were used for protoplasts isolation (Loesch-Fries et al., 1985). "Each image-frame expressing GFP represents the visualization of several protoplasts (about 15-20) per assay for each protein combination analyzed" (Leastro et al., 2017b). GFP expression in protoplast was analyzed with a Zeiss LSM 780 confocal laser-scanning microscope.

\section{Alfalfa Mosaic Virus Assay}

For analyses of cell-to-cell movement, the cassette from plasmids containing all proteins assayed inserted into AMV 3 cDNA, was amplified with specific primer pairs, and the generated amplicons were used directly as templates for in vitro transcription with T7 RNA polymerase (Takara Bio Inc., United States). For $M P, N$, and $P$ co-inoculation, we balanced the concentration of AMV RNA3 transcripts carrying the heterologous genes. The quantification was performed with agarose gel electrophoresis using an RNA ladder (RiboRuler High Range RNA Ladder, Thermo Scientific) and several dilutions of the transcribed RNAs. Next, transgenic N. tabacum P12 plants that express the polymerase proteins P1 and P2 of AMV (van Dun et al., 1988) were grown and inoculated with RNA transcripts, as previously described (Taschner et al., 1991). The chimeric AMV RNA 3 expressing the AMV MP wild type (wt) was obtained from Leastro et al. (2017b). As reviewed by Leastro et al. (2020), three independent experiments were performed, each one included the infiltration of three leaves of P12 plants per construct. The foci images in P12 plants were taken with the aid of a Leica MZ16F fluorescence stereomicroscope.

\section{Turnip Crinkle Virus Complementation Assay}

This system is based on the in trans complementation of the movement-deficiency phenotype of a TCV MP deletion mutant that expresses GFP (TCV $\triangle 92$-sGFP) (Powers et al., 2008). The trans-complementation assay was performed as previously described by Martinez-Perez et al. (2019). In short, three leaves 
of $N$. benthamiana per plant were infiltrated with A. tumefaciens cultures containing the empty pMOG $_{800}$ or expressing the LEP protein (negative controls), MP of CiLV-C (positive control) (both obtained from Leastro et al., 2020) or the $\mathrm{pMOG}_{800}$ constructs expressing the CiLV-N or OFV-citrus MPs at OD 6001. Next, the pTCV $\triangle 92$-sGFP plasmid was linearized with $\mathrm{XbaI}$ and transcripts were inoculated at 1 day post infiltration. TCV $\Delta 92$ sGFP infectious RNA transcripts were mechanically inoculated onto the abaxial surfaces of the infiltrated leaves. Cell-to-cell movement was evaluated at 3 days after inoculation, with a
Leica MZ16F fluorescence stereomicroscope. Each assay was repeated three times.

\section{Tobacco Mosaic Virus Complementation Assay}

The pDsRedTMV-wt plasmid (provided by Dr. S. Chapman, Scottish Crop Research Institute) (Canto and Palukaitis, 2002) carrying a tobacco mosaic virus (TMV) infectious clone expressing the DsRed fluorescent protein, was modified to

TABLE 3 | Protein pair combinations performed in the BiFC heterologous assays.

\begin{tabular}{|c|c|c|c|c|c|}
\hline Heterologous assays & $\begin{array}{l}\text { p29/MP } \\
\text { CiLV-C2 }\end{array}$ & $\begin{array}{l}\text { N/MP } \\
\text { CiLV-N }\end{array}$ & $\begin{array}{c}\text { P/N } \\
\text { CiLV-N }\end{array}$ & $\begin{array}{c}\text { P/MP } \\
\text { CiLV-N }\end{array}$ & $\begin{array}{l}\text { N/MP } \\
\text { OFV }\end{array}$ \\
\hline ORF-NYFP + ORF-CYFP & + & + & - & + & - \\
\hline ORF-NYFP + CYFP-ORF & - & - & + & + & - \\
\hline NYFP-ORF + ORF-CYFP & - & - & - & + & - \\
\hline NYFP-ORF + CYFP-ORF & - & - & + & + & + \\
\hline ORF-CYFP + ORF-NYFP & + & - & + & + & - \\
\hline ORF-CYFP + NYFP-ORF & - & - & + & + & - \\
\hline CYFP-ORF + ORF-NYFP & + & - & + & + & - \\
\hline CYFP-ORF + NYFP-ORF & - & + & + & + & - \\
\hline \multicolumn{6}{|l|}{ Negative controls } \\
\hline CYFP-ORF + NYFP-cyt & - & - & - & - & - \\
\hline ORF-CYFP + NYFP-cyt & - & - & - & - & - \\
\hline \multirow[t]{3}{*}{ NYFP-ORF + CYFP-ER } & - & - & - & - & - \\
\hline & $\mathbf{P} / \mathbf{N}$ & P/MP & p29 CiLV-C/ & MP CiLV-C/ & p29 CiLV-C/ \\
\hline & OFV & OFV & p29 CiLV-C2 & MP CiLV-C2 & MP CiLV-C2 \\
\hline ORF-NYFP + ORF-CYFP & - & + & + & - & - \\
\hline ORF-NYFP + CYFP-ORF & + & + & + & - & - \\
\hline NYFP-ORF + ORF-CYFP & + & - & + & - & - \\
\hline NYFP-ORF + CYFP-ORF & + & + & + & - & - \\
\hline ORF-CYFP + ORF-NYFP & + & + & + & - & + \\
\hline ORF-CYFP + NYFP-ORF & + & + & + & - & - \\
\hline CYFP-ORF + ORF-NYFP & + & + & + & - & + \\
\hline CYFP-ORF + NYFP-ORF & + & + & + & - & - \\
\hline \multicolumn{6}{|l|}{ Negative controls } \\
\hline CYFP-ORF + NYFP-cyt & - & - & - & - & - \\
\hline ORF-CYFP + NYFP-cyt & - & - & - & - & - \\
\hline \multirow[t]{2}{*}{ NYFP-ORF + CYFP-ER } & - & - & - & - & - \\
\hline & $\begin{array}{l}\text { p29 CiLV-C2/ } \\
\text { MP CiLV-C }\end{array}$ & $\begin{array}{c}\text { N CiLV-N/ } \\
\text { N OFV }\end{array}$ & $\begin{array}{l}\text { MP CiLV-N/ } \\
\text { MP OFV }\end{array}$ & $\begin{array}{l}\text { N CiLV-N/ } \\
\text { MP OFV }\end{array}$ & $\begin{array}{c}\text { N OFV/ } \\
\text { MP CiLV-N }\end{array}$ \\
\hline ORF-NYFP + ORF-CYFP & - & + & - & - & - \\
\hline ORF-NYFP + CYFP-ORF & + & + & - & - & + \\
\hline NYFP-ORF + ORF-CYFP & - & - & + & - & - \\
\hline NYFP-ORF + CYFP-ORF & - & + & - & - & - \\
\hline ORF-CYFP + ORF-NYFP & + & - & + & - & - \\
\hline ORF-CYFP + NYFP-ORF & + & - & + & - & - \\
\hline CYFP-ORF + ORF-NYFP & + & + & + & - & - \\
\hline CYFP-ORF + NYFP-ORF & - & - & + & - & + \\
\hline \multicolumn{6}{|l|}{ Negative controls } \\
\hline CYFP-ORF + NYFP-cyt & - & - & - & - & - \\
\hline ORF-CYFP + NYFP-cyt & - & - & - & - & - \\
\hline NYFP-ORF + CYFP-ER & - & - & - & - & - \\
\hline
\end{tabular}




\begin{tabular}{|c|c|c|c|c|c|}
\hline & & & & & $\begin{array}{c}\text { Intra-association } \\
\text { control }\end{array}$ \\
\hline & $\begin{array}{l}\text { MP CiLV-C2/ } \\
\text { MP OFV }\end{array}$ & $\begin{array}{c}\text { p29 CiLV-C2/ } \\
\text { N OFV }\end{array}$ & $\begin{array}{l}\text { p29 CiLV-C2/ } \\
\text { MP OFV }\end{array}$ & $\begin{array}{c}\text { MP CiLV-C2/ } \\
\text { N OFV }\end{array}$ & $\begin{array}{l}\text { MP CiLV-C/ } \\
\text { p24 CiLV-C }\end{array}$ \\
\hline ORF-NYFP + ORF-CYFP & + & + & - & - & - \\
\hline ORF-NYFP + CYFP-ORF & - & + & - & - & - \\
\hline NYFP-ORF + ORF-CYFP & + & - & - & - & - \\
\hline ORF-CYFP + ORF-NYFP & - & + & + & - & - \\
\hline ORF-CYFP + NYFP-ORF & - & + & + & - & - \\
\hline CYFP-ORF + ORF-NYFP & + & + & + & - & - \\
\hline CYFP-ORF + NYFP-ORF & - & + & - & - & - \\
\hline Negative controls & & & & & \\
\hline \multicolumn{6}{|c|}{ Inter-association controls } \\
\hline & $\begin{array}{l}\text { CP AMV/ } \\
\text { MP CiLV-C }\end{array}$ & $\begin{array}{l}\text { N TSWV/ } \\
\text { MP CiLV-C }\end{array}$ & & & \\
\hline
\end{tabular}

\begin{tabular}{lcc}
\hline ORF-NYFP + ORF-CYFP & - & - \\
ORF-NYFP + CYFP-ORF & - & - \\
NYFP-ORF + ORF-CYFP & - & - \\
NYFP-ORF + CYFP-ORF & - & - \\
ORF-CYFP + ORF-NYFP & n.d & - \\
ORF-CYFP + NYFP-ORF & n.d & - \\
CYFP-ORF + ORF-NYFP & n.d & - \\
CYFP-ORF + NYFP-ORF & n.d & - \\
Negative controls & & - \\
CYFP-ORF + NYFP-cyt & - & - \\
ORF-CYFP + NYFP-cyt & - & - \\
NYFP-ORF + CYFP-ER & - &
\end{tabular}

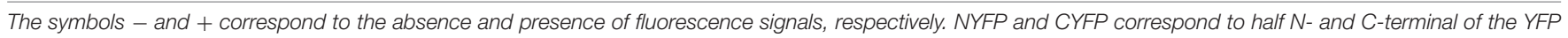
protein, respectively. OFV = OFV-citrus. n.d=non-determined. Additional negative controls are presented for intra- and inter-association assays.

eliminate the $M P$ gene (pDsRedTMV- $\triangle \mathrm{MP}$ ). The new TMV construct was linearized with $K p n I$ and transcribed with T7 RNA polymerase. The infectious TMV transcripts were inoculated onto $N$. benthamiana leaves, previously infiltrated (1 day) with A. tumefaciens cultures containing the $\mathrm{pMOG}_{800}$ constructs expressing the LEP protein (negative control), MP of CiLV$\mathrm{C}$ (positive control), or the CiLV-N or OFV-citrus MPs at an $\mathrm{OD}_{600} 1$, as described above. The fluorescent signal was monitored at 3 days post inoculation with a Leica MZ16F fluorescence stereomicroscope.

\section{RESULTS}

\section{Dichorhavirus MPs Are Membrane Proteins, While Ns Are Not Membrane-Associated}

Association between movement proteins and host membranes seems to be an essential factor for virus transport, being a feature constantly identified in this class of viral proteins (Peremyslov et al., 2004; Martínez-Gil et al., 2009; Peiro et al., 2014b; Leastro et al., 2015; Pitzalis and Heinlein, 2017; Leastro et al., 2018). Thus, in order to analyze membrane association of dichorhavirus MP and N, we prepared subcellular microsomal fraction from $N$. benthamiana leaves transiently expressing the CiLV-N N, CiLV-N MP, OFV-citrus N, and OFV-citrus MP proteins fused to the HA epitope. As controls, we used leaf protein extracts containing transiently expressed free eGFP and the HA-tagged Lep protein, which are, respectively, non-membrane and integral membrane proteins (Peiro et al., 2014b; Leastro et al., 2018). High-speed ultracentrifugation was performed to separate the plant leaf lysed extract, containing the above mentioned proteins, into pellet (P30) and supernatant (S30) fractions. To identify the type of interaction, we first washed the membrane-rich fraction from each sample with $\mathrm{Na}_{2} \mathrm{CO}_{3}$, to release soluble luminal proteins from microsomes (Peremyslov et al., 2004; Leastro et al., 2015, 2018). With this treatment, most of the CiLV-N and OFVcitrus MPs remained associated with the membranous fraction 
(Figure 1A, P30 72\% for CiLV-N MP and 97\% for OFV-citrus $\mathrm{MP}$ ), suggesting that these proteins are tightly associated with membranes. As expected, the integrated membrane Lep protein control also remained associated with the membranous fraction (Figure 1A, P30 99\%). In agreement with the non-membrane associated GFP control, a considerable portion of the $\mathrm{N}$ proteins

A

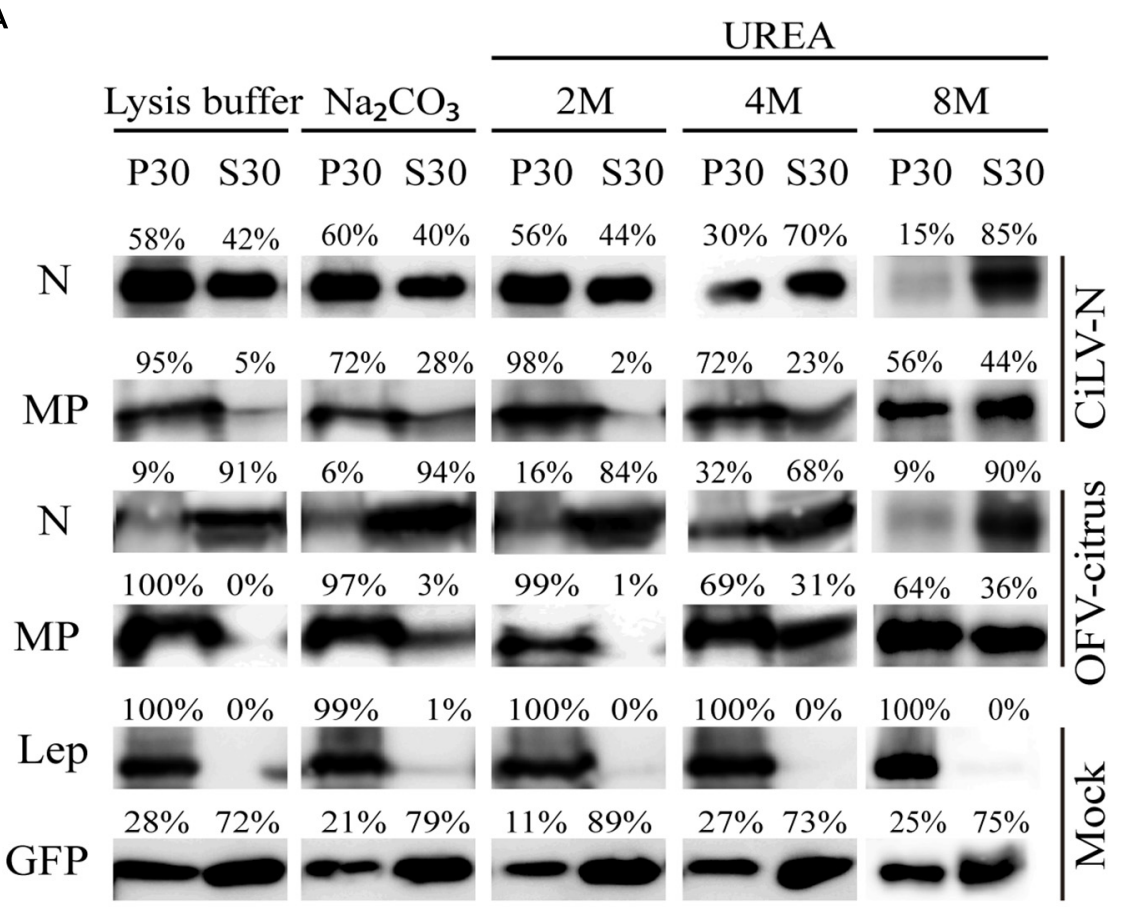

B $1 \%$ Triton X-114

\begin{tabular}{lrrrrr}
\hline P30 & OP & AP & P30 & OP & AP \\
& $17 \%$ & $83 \%$ & & $100 \%$ & $0 \%$
\end{tabular}
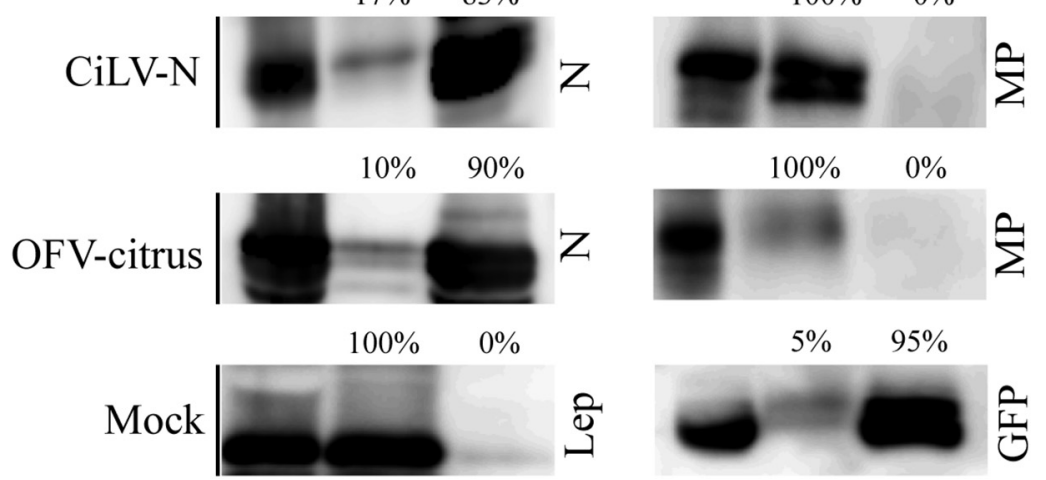

FIGURE 1 | Membrane association analysis of dichorhavirus MP and N proteins. (A) Separation into membranous and soluble fraction of CiLV-N and OFV-citrus MP and $\mathrm{N}$ proteins expressed in planta. Respective proteins targeted with HA were expressed in Nicotiana benthamiana leaves by agroinfiltration. As controls, we used leaf protein extracts containing unfused expressed eGFP (non-membrane) and the HA-tagged Lep (leader peptidase) (integral membrane) proteins, respectively. The supernatant from ultracentrifugation after membrane fractioning (S30), and comparable pellet (P30), untreated and alkaline or urea (2M, 4M, and 8M) treatments were analyzed by Western blot method using an anti-NtGFP antibody (Sigma-Aldrich, Steinheim, Germany) or anti-HA antibody (Thermo Fisher Scientific, Waltham, MA, United States). Relative quantification values are presented. (B) Triton X-114 partitioning assay of CiLV-N and OFV-citrus MPs and Ns. The P30 fractions subjected to treatment with Triton X-114 were separated in aqueous (AP) and organic (OP) phases. Equivalent amounts of fractions were analyzed by Western blot, and the same controls mentioned above were used. 
remained in the soluble fraction (Figure 1A, S30 40\% for CiLV$\mathrm{N} \mathrm{N}, 94 \%$ for OFV-citrus $\mathrm{N}$ and $79 \%$ for GFP), suggesting that these proteins are not associated with host membrane. After the sequential $2 \mathrm{M}, 4 \mathrm{M}$, and $8 \mathrm{M}$ urea treatment, all polypeptides bound to membranes should be released, except for the integral membrane proteins (Martínez-Gil et al., 2009; Leastro et al., 2015, 2018). The HA-tagged MPs were also detected in the soluble fraction (Figure 1A, 8M 44\% for CiLV-N MP and 36\% for OFVcitrus MP), in contrast with the Lep control that remained in the pellet fraction (Figure 1A, 8M 100\%). This result suggests that dichorhavirus MP might be a peripheral protein tightly associated to membrane.

To further investigate the membrane association of the MPs and $\mathrm{N}$ proteins, a Triton $\mathrm{X}-114$ partitioning assay was performed. In this treatment, two aqueous (AP) and organic phases (OP) are formed, in which integral membrane proteins should be portioned into the OP, while the AP should contain solube and non-integral membrane proteins (Bordier, 1981). When the P30 fractions were treated with Triton X-114, the dichorhavirus MPs were detected mostly in the OP, whereas the $\mathrm{N}$ proteins were associated to the AP (Figure 1B). As expected, the Lep and GFP control proteins were recovered from OP and AP, respectively (Figure 1B). Collectively, these findings indicate that the membrane insertion capability of the MPs lies between an integral membrane protein and a peripheral membrane protein, where probably these MPs do not span the lipid bilayer. For the $\mathrm{N}$ proteins, they behave as non-membrane associated proteins.

\section{The Termini of the Dichorhavirus MPs Are Oriented Toward the Cytoplasmic Face of the Biological Membranes}

BiFC assays were performed to determine the subcellular compartments in which the $\mathrm{N}$ - or C-termini of the dichorhavirus MPs are exposed. As additional controls, we also tested the $\mathrm{N}$ proteins, although they are not membrane-associated proteins. BiFC constructs containing the MPs or Ns of CiLV-N and OFV-citrus were co-expressed with the counterpart of EYFP targeted to the endoplasmic reticulum (ER) (C-YFPer or $\mathrm{N}$-YFPer) or to the cytosol/nucleus (C-YFPcyt or N-YFPcyt). For this BiFC topological assay, all protein pair combinations are shown in Table 1. "Reconstitution of the fluorescencecompetent EYFP structure indicated the in vivo localization of the fused/inserted YFP half in the appropriate compartment" (Leastro et al., 2018). Confocal images showed fluorescence reconstitution when the two halves of the EYFP were coexpressed in the same subcellular compartment (N-YFPcyt $+\mathrm{C}$ YFPcyt or N-YFPer + C-YFPer; Figures 2Ai,ii). However, no fluorescence signal was revealed when the two EYFP were coexpressed in different compartments (N-YFPcyt + C-YFPer or N-YFPer + C-YFPcyt; Figures 2Aiii,iv). For NYFP-MPs and MPs-NYFP, the reconstitution of the fluorescence was only observed when the respective proteins were co-expressed with C-YFPcyt, indicating that MPs termini were exposed to cytosolic compartment (Figures 2Bix,x,Cxvii,xviii). Also, fluorescence signal was visualized into the nucleus (see red arrows), suggesting the capability of these MPs to access this compartment but also indicating that both termini of the proteins are exposed to the inner part of the nucleus. Similar results were observed using the non-associated membrane $\mathrm{N}$ proteins, in which part of the fluorescence reconstitution was observed in the cytoplasm and part into the cell nuclei (Figures 2Bv,vi,Cxiii,xiv; red arrows indicate the nuclei), indicating the presence of this protein both in the cytoplasm and in the nucleus. No fluorescent reconstitution was observed when both MP and $\mathrm{N}$ proteins, fused to any of the YFP fragments, were coexpressed with the counterpart of the YFP addressed to the ER (Figures 2Bvii,xi,Cxv,xix). Taken together, these results show that the $\mathrm{N}$ - and C-termini of the dichorhavirus MPs are oriented toward the cytoplasmic face of the biological membrane and also into the inner part of the nucleus membrane.

\section{Subcellular Localization of the MP, N, and P Proteins}

The OFV (orchid strain) N-P protein complex is associated in the inner part of the cell nuclei, which are thought to represent the viroplasm-like structure (Kondo et al., 2013). In order to expand the understanding about dichorhavirus transport mechanism, we evaluated the intracellular distribution of the N-P complex in presence of the cognate MP, as well as the putative interaction among the three proteins. We first characterized the intracellular localization of the MP, N, and $\mathrm{P}$ proteins from two different dichorhaviruses (CiLV-N and OFV-citrus). The proteins, carrying the eGFP at their $\mathrm{N}$ - or C-termini were transiently expressed in N. benthamiana leaves, alone or with a nuclear marker. The fluorescent GFP signal derived from both MPs was visualized into the nuclei and along the cell periphery. However, the intranuclear distribution of the CiLV-N MP:eGFP was organized in fluorescent punctate bodies, while the OFV-citrus MP:eGFP generated a diffuse signal (Figures 3Aa,b, respectively), similar to that observed for the free eGFP (Control, Figure 3B, cell panels), which colocalized with the nuclear marker. A quantitative analysis of 100 fluorescent cells revealed that the nuclear localization of CiLV-N MP and OFV-citrus MP was observed in 25 and $100 \%$ of the cells, respectively (Figure $\mathbf{3 A}$, cell panels). Finally, the infiltration of fluorochrome aniline blue (a plasmodesmata marker staining the callose) on $N$. benthamiana leaves expressing the respective MPs, revealed that the MP-derived punctate structures observed at the cell periphery colocalize with callose deposits (Figures 3Ac,d), suggesting its association with PD. No punctate structures were observed in the negative control expressing free GFP (data not shown).

Previous results showed that individual ectopic expression of $\mathrm{P}$ and $\mathrm{N}$ proteins of $\mathrm{OFV}$ (orchid strain) are localized predominantly into the nucleus and the cytoplasm of $N$. benthamiana leaves, respectively (Kondo et al., 2013). The fluorescent signal derived from the transient expression of the OFV N:eGFP (citrus strain) was visualized in the cytoplasm but also in the nuclei of 19\% (19 out of 100) fluorescent cells (Figure 3B, cell panel and Figures 3Bd,e). Similar fluorescent pattern was observed from the transiently expressed CiLV-N $\mathrm{N}$ :eGFP construct, except for the higher percentage of cells (56\%; 


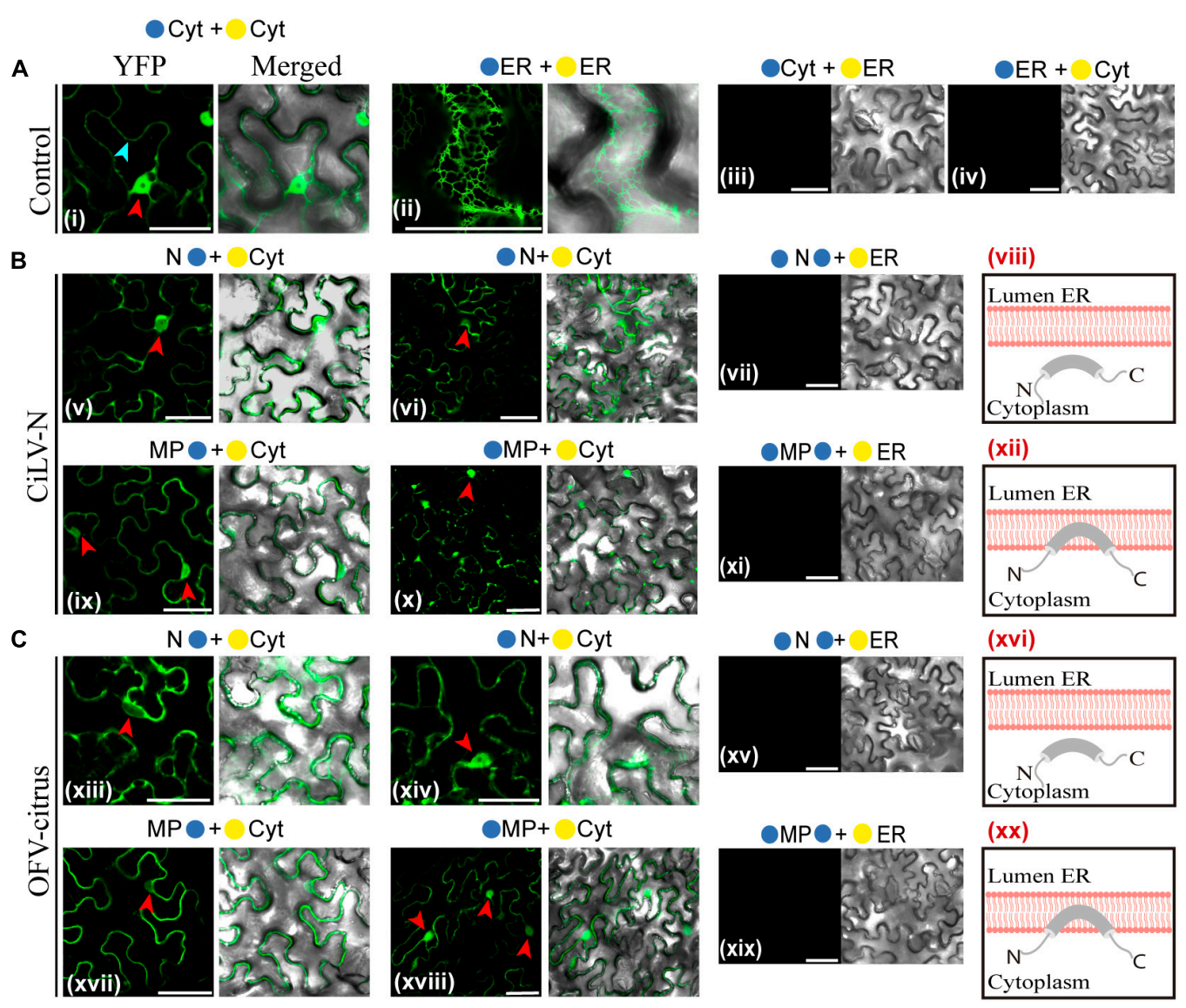

FIGURE 2 | Dichorhavirus MPs are associated to membrane with their termini exposed to the cytosol. Subcellular localization (cytosolic face or ER lumen) of the N-

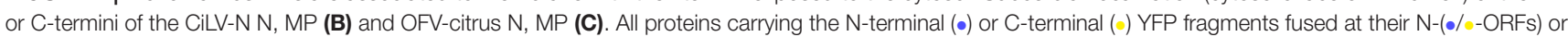
C-termini (ORFs- $\bullet$ ) were transiently co-expressed in $N$. benthamiana leaves with corresponding complementary YFP fragment addressed to the cytosol face ( $\bullet-c y t$ or -cyt) or the lumen of the ER ( $\bullet$-ER or -ER). Images reveal the topology of the C-termini (v,ix,xiii,xvii) or N-termini (vi, x, xiv, and xviii) of the respective dichorhavirus proteins. Red and blue arrows indicate the cell nucleus and cytoplasm, respectively. Positive and negative controls are presented in (A). Hypothetical topologic models are presented at the panels to the right of the figure for each respective protein (viii,xii, $x \mathrm{vi}, \mathrm{xx}$ ). All images contain two pictures corresponding to the YFP signal or merged with bright field. The fluorescence was monitored at 4 days post-infiltration using a confocal Zeiss LSM 780 model. Bars correspond to $50 \mu \mathrm{m}$.

56 out of 100) showing fluorescence into the nuclei (Figure 3B, cell panels, Figures $\mathbf{3 B b}, \mathbf{c})$. Finally, the fluorescent signal derived from the P:eGFP proteins was predominantly located into the cell nuclei for both dichorhaviruses (Figures 3Ca,b).

For some dichorhavirus proteins, the presence of the eGFP at their $\mathrm{N}$ termini (i.e., eGFP-MP) revealed an impairment in the protein subcellular localization (data not shown). Accordingly, here we present the subcellular localization of constructs containing the free $\mathrm{N}$-termini.

\section{The MP Dimerizes and Associates With the $\mathrm{N}$ and $\mathrm{P}$ Proteins, in vivo}

Next, BiFC analyses were performed to address the capability of interaction between the MP with the N-P complex. To do this, the MPs, Ns, and Ps of CiLV-N and OFV-citrus were fused at their $\mathrm{N}$ - or C- termini with the NYFP or CYFP fragments, and transient expression of different fusion protein pair combinations was performed (Table 2) by agroinfiltration of $N$. benthamiana leaves. First, we evaluated the dimer formation for the three proteins. Reconstitution of YFP fluorescence localized along the cell periphery and nucleus was visualized for the CiLV-N and OFV-citrus MPs (Figures $\mathbf{4 A b}, \mathbf{B b}$, respectively), suggesting the capacity of this protein to self-interact. The suggested dimer formation was also visualized for the $\mathrm{N}$ and $\mathrm{P}$ proteins of both OFV-citrus (Figures 4Aa,c) and CiLV-N (Figures 4Ba,c). The reconstituted fluorescence signal derived from the $\mathrm{N}$ dimerization was distributed throughout the cytoplasm and some nuclei; meanwhile, $\mathrm{P}$ dimerization was predominantly into the nucleus. No fluorescence signal was observed when the MPs, Ns, and Ps carrying the CYFP fragment fused at their $\mathrm{N}$ - or C-termini were co-expressed with the counterpart NYFP targeted to the cytosol or to the ER (negative controls, Figure 4C).

Next, we evaluated the heterologous association between the proteins. Reconstitution of the fluorescence was observed for the combinations between N-MP, P-N, 
A
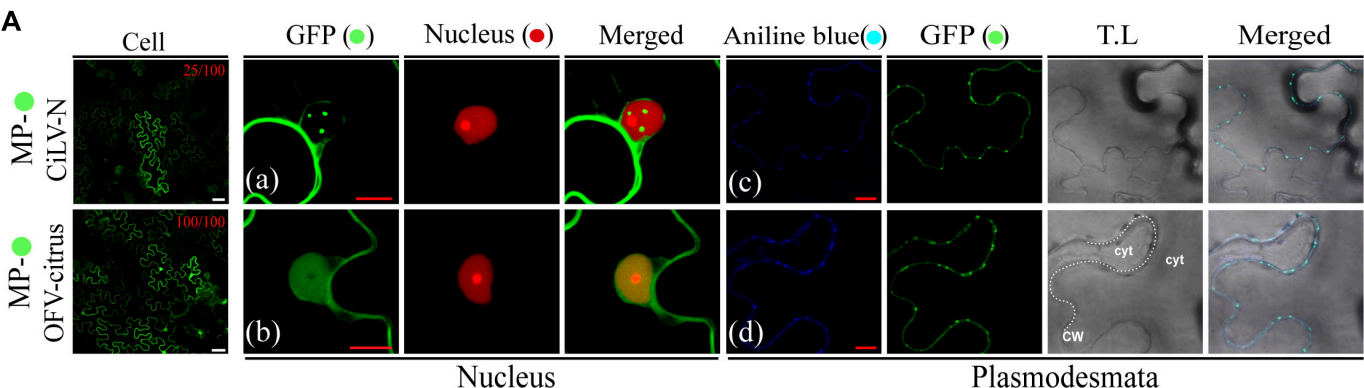

Nucleus

Plasmodesmata

B
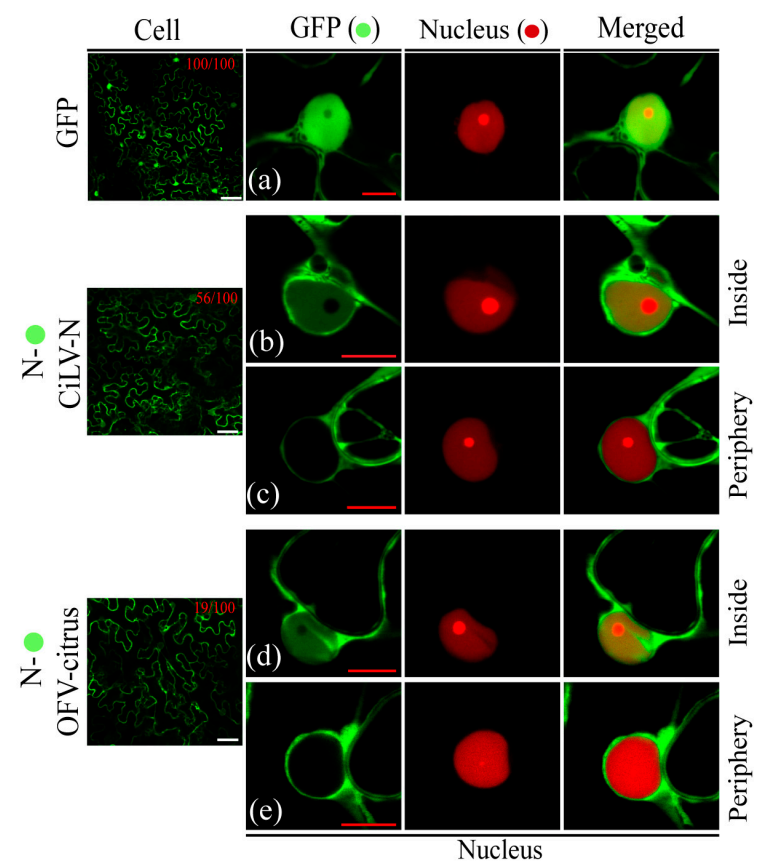

C

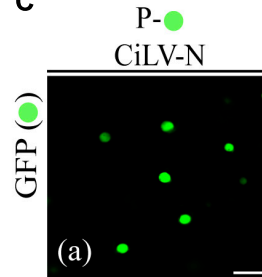

P-○
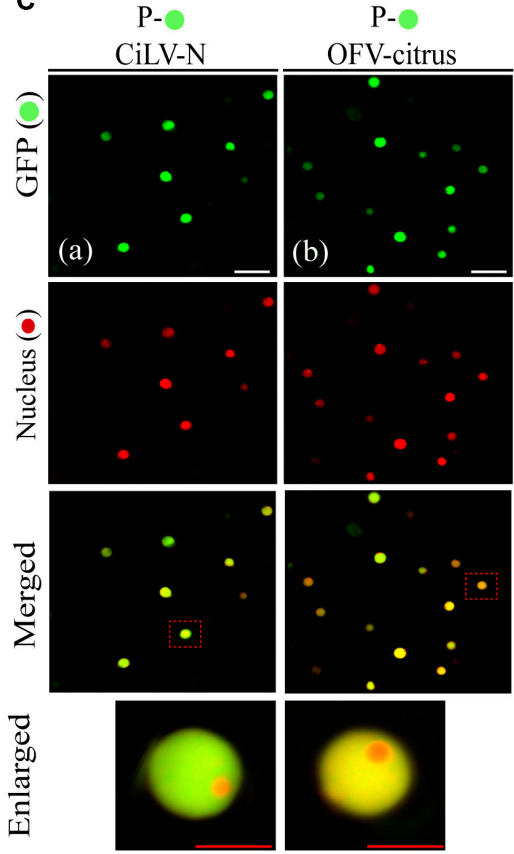

FIGURE 3 | Intracellular distribution and structure formation from ectopic expression of the dichorhavirus MPs, Ns, and Ps. The CiLV-N and OFV-citrus MP, N, and P fused at their C-termini with eGFP $(\bullet)$ were co-expressed with $\mathrm{mRFP}(\bullet)$ nucleus marker or aniline blue (•) fluorochrome (plasmodesmata marker) in epidermal cells of $N$. benthamiana. Fluorescence signals were captured $48-72 \mathrm{~h}$ post-infiltration with confocal microscope Zeiss LSM 780 model. The green (GFP), red (mRFP) channels, and merged images are shown for each protein expressed with nucleus marker. The blue (aniline blue), green, transmitted light (T.L), and merged images are shown for MP expressed with plasmodesma marker. The dotted line in the transmitted light image indicates the cell wall (CW). Cyt $=$ cytoplasm. The numbers at the top of cell panels correspond to the number of fluorescent cells showing fluorescence in the nucleus, i.e., 25/100 indicates that 25 out of 100 fluorescent cells showed the presence of GFP in the nuclei. The free-eGFP expression is located as a diffuse signal distributed in the cytoplasm and nucleus (Ba). (A) Image shows the CiLV-N MP-• expression in punctate structures into the nuclei co-localizing with nuclei marker (a), and a signal distributed at cell membrane periphery, colocalized in punctate structures with plasmodesmata along the cell periphery (c). (b) OFV-citrus MP-• expression in a diffuse signal evenly distributed into the nucleus co-localizing with nuclei marker, and co-localizing in punctate structures with plasmodesmata along the cell periphery (d). (B) CiLV-N and OFV-citrus N-。 expression in a diffuse signal distributed within some cell nuclei co-localizing with nuclei marker (b and $\mathbf{d})$. GFP-empty nuclei are also visualized (c and $\mathbf{e})$. $\mathrm{N}$-。 signal is also distributed throughout the cytoplasm for both viruses. (C) The P-॰ expression is visualized exclusively in cell nuclei colocalized with nuclei marker for both CiLV-N (a) and OFV-citrus (b). Images below show in higher magnification the respective nuclei indicated in the red dashed boxes. Red and white bars correspond to 10 and $50 \mu \mathrm{m}$, respectively.

and MP-P for both dichorhaviruses (Figures 4Ad-f for CiLV-N and Figures $\mathbf{4 B d}-\mathbf{f}$ for OFV-citrus). The same negative controls presented in the dimerization assay were also applied to the heterologous interactions. Table 3 summarizes all findings of the transient heterologous combination and reports all different fusion protein pair combinations performed. The fluorescence reconstitution from the interaction between the $\mathrm{N}$ and MP proteins was observed spread throughout the cytoplasm for CiLV-N, mostly visualized to the cell periphery (Figure 4Ad). In contrast, for OFV-citrus, it was localized more expressively into the nucleus, but also in lesser amounts in the cell periphery when compared to CiLV-N (Figure 4Bd). For both dichorhaviruses, the P-N capsid complex was localized predominantly into the nuclei (Figures 4Ae,Be). For CiLV-N, the MP-P complex was distributed into 
A

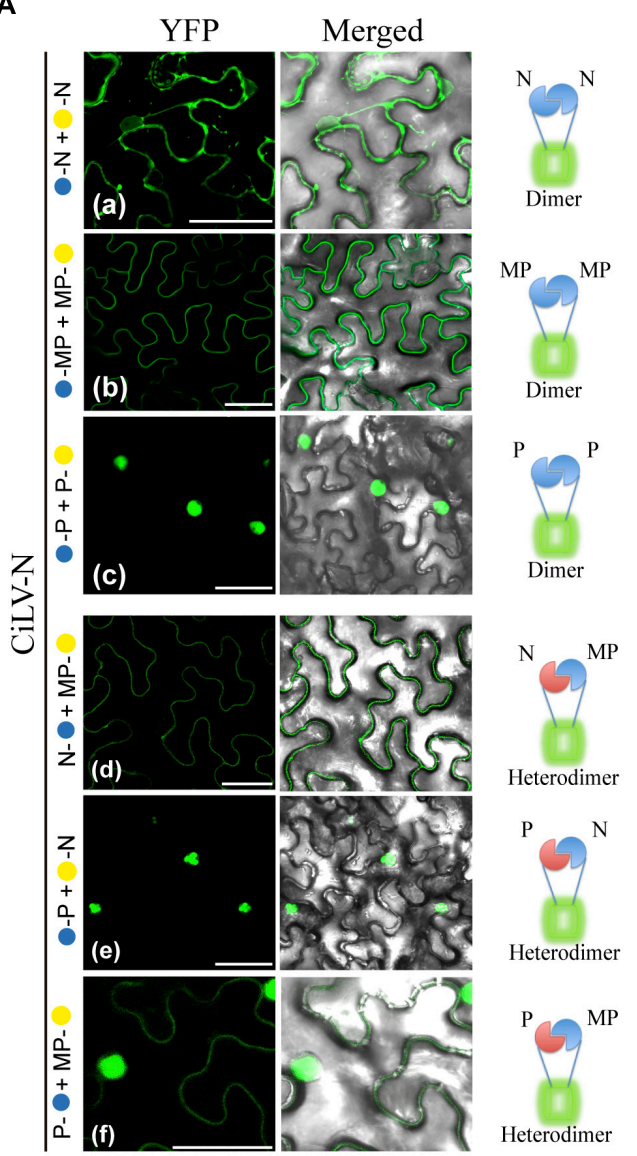

B

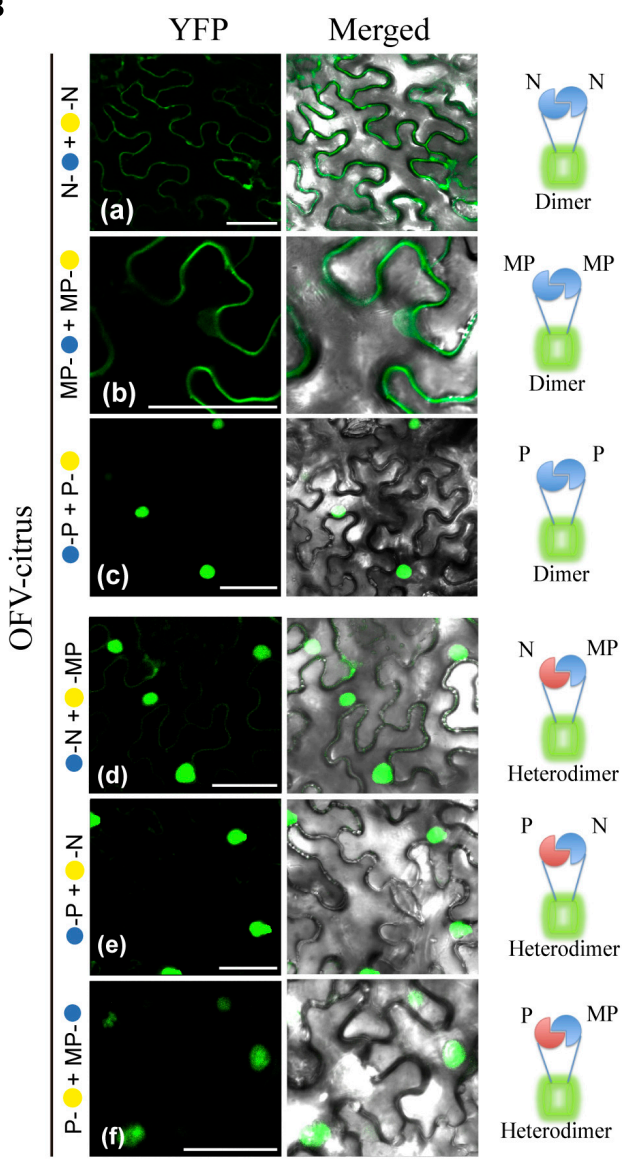

C

Negative controls

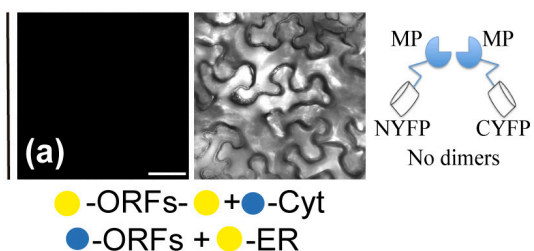

FIGURE 4 | BiFC analyses suggest dimer and heterologous interactions between dichorhavirus MP, N, and P. CiLV-N and OFV-citrus Ns, Ps and MPs carrying

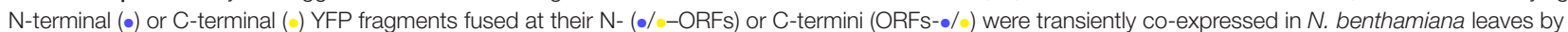
agroinfiltration. Confocal microscopy images corresponding to the representative fusion protein pair combination assayed for dimeric and heterologous interactions. Representative protein pair combinations are indicated at the left of each image; all combinations performed are shown in Tables 2, 3. All images contain two pictures corresponding to the YFP signal or merged with bright field. (Aa) CiLV-N and (Ba) OFV-citrus N dimerizations with YFP signal located in the nucleus and cytoplasm. (Ab) CiLV-N and (Bb) OFV-citrus MP dimerizations with YFP signal located along the cell periphery and also visualized into the nucleus. (Ac) CiLV-N and (Bc) OFV-citrus P dimerizations with YFP signal exclusively localized into the nuclei. (Ad) CiLV-N N-MP intra-association with YFP signal distributed along the cell periphery, while for OFV-citrus N-MP (Bd) intra-association the YFP signal is more evident into the nuclei, but also located throughout cytoplasm. (Ae) CiLV-N and (Be) OFV-citrus P-N associations showing the YFP fluorescence reconstitution into the nuclei. (Af) CiLV-N P-MP association results in YFP signal in the nucleus and distributed along the cell periphery, while for OFV-citrus P-MP (Bff), the YFP signal is exclusively into the nucleus. (C) Negative controls correspond to the expression of the dichorhavirus proteins in combination with Cyt or ER BiFC vectors. The left of each image has a representative scheme of the positive (dimers) or negative (no dimers) interaction corresponding to all proteins assayed. All images displayed are representative of at least three independent experiments. Bars correspond to 50 $\mu \mathrm{m}$.

the nuclei and in the cell periphery (Figure 4Af), in contrast to the OFV-citrus, where the reconstitution of the fluorescence was visualized predominantly into the nucleus (Figure 4Bf).
These observations reveal an interaction network formed among the MP, N, and $\mathrm{P}$ dichorhaviruses proteins, indicating a role of the MP in recruiting $\mathrm{N}$ and $\mathrm{P}$ to the cell periphery, most evident in the analysis with CiLV-N proteins. 


\section{Dichorhavirus MP Mediates the Relocalization of N Protein From the N-P Core Complex to the Plasmodesma Structures}

To obtain additional insights about the interaction and localization patterns of dichorhavirus MPs, Ns, and Ps in cell plants, we evaluated whether the characterized N-P intranuclear viroplasm complex could be rearranged from the co-expression with the cognate MP. For this purpose, initially by the expression of two protein pair combination of the MPs, Ns and Ps fused at their C-termini with GFP or RFP, we analyzed the intracellular redistributions of the proteins in $N$. benthamiana leaves. The co-expression of the N:GFP and P:RFP clearly redistributed the $\mathrm{N}$ protein from the cytoplasm to the nucleus for both viruses (Figures $5 \mathbf{A a}, \mathbf{B a}$ ). When we evaluated the localization of the P:RFP in the presence of MP:eGFP, we did not detect any disturbance in the localization of each protein of both viruses. Part of the MP was maintained into the nucleus, but a larger part of it localized at the cell periphery, whereas the $\mathrm{P}$ protein remained predominantly into the nucleus (Figures $5 \mathbf{A b}, \mathbf{B b}$ ), which is in disagreement with what was observed in $\mathrm{BiFC}$ analysis. On the other hand, when the MP:eGFP of CiLV-N was co-expressed with its cognate $\mathrm{N}$ protein tagged with the HA epitope (N:HA), the punctate MP structures visualized in some cell nuclei from leaves expressing only the MP:eGFP construct (see white arrow in Figures 3Aa, 5Acii) were no longer visualized (Figure 5Ac), suggesting that the $\mathrm{N}$ could aid the release of the MP from the nucleus to the cytoplasm. There were no changes in the localization of the CiLV-N N protein when co-expressed with its cognate MP:HA (compare Figure 5Ad with Figure 3Bb), which remained in the nucleus and in the cytoplasm. For the OFV-citrus, the co-expression of the MP:eGFP with the cognate $\mathrm{N}: \mathrm{HA}$ did not affect MP distribution, which remained in both the nucleus and the cytoplasm (Figure 5Bc). However, the coexpression of the N:eGFP construct with the cognate MP:HA modified the nuclear localization observed for the $\mathrm{N}$ protein when it was expressed alone, being localized exclusively in the cytoplasm (Figure 5Bd), indicating that OFV-citrus MP redirects the $\mathrm{N}$ from the nucleus to the cell cytoplasm.

The observation that MP associates with $\mathrm{N}$ and $\mathrm{P}$ and can direct these proteins from the nucleus to the cell cytoplasm, suggests that the intranuclear N-P viroplasm complex could be transported out of the nucleus by the MP, in order to ensure the transport of infectious components or viral subcomplexes across the cytoplasm to neighboring cells. To address this hypothesis, we evaluated the redistribution of the intranuclear $\mathrm{N}-\mathrm{P}$ complex of both OFV-citrus and CiLV-N by tagging $\mathrm{N}$ and $\mathrm{P}$ proteins with the GFP and RFP markers, respectively. The co-expression of the $\mathrm{N}$ and $\mathrm{P}$ proteins with the cognate MP:HA revealed that the N:GFP signal, seen exclusively into the nucleus in association with $\mathrm{P}$ (Figures 4Ae,Be, 5Aa,Ba; also see Kondo et al., 2013), was partially redirected to the cytoplasm in presence of MP, while no changes were observed for the P:RFP localization (Figures 5Ae,Be). It is noteworthy to mention that N-P colocalization signals continued to be evident in the subnuclear regions (Figures $5 \mathbf{A e}, \mathbf{B e}$ ). Callose staining with aniline blue confirmed that the N:eGFP signal was redirected to the plasmodesmata at the cell periphery (Figure 5Af,Bf). These data were consistent for both CiLV-N and OFV-citrus proteins. Taken together, these findings indicate that the MP redirects the $\mathrm{N}$, but not the N-P core complex, to PD at the cell periphery.

\section{The Dichorhavirus MPs Do Not Complement the Movement-Deficiency Phenotype of AMV, TCV, and TMV Infectious Mutants}

To further explore the functionality of the dichorhavirus MPs, we tentatively evaluated their intrinsic movement proprieties using two distinct approaches: cis- and trans-movement complementation analyses. For cis-movement complementation assay, the MP genes of CiLV-N and OFV-citrus were inserted into the AMV RNA3 infectious construction that expresses the GFP (pGFP/A255/CP), fused or not with the C-terminal 44 amino acids of the AMV MP (A44) (Sanchez-Navarro et al., 2001) by exchanging the AMV MP gene expressing the N-terminal 255 residues (A255). The presence of the A44 region at the C-terminus of the heterologous MPs allows the interaction between the heterologous MPs and the AMV coat protein. The AMV system permits the functional exchangeability of viral MPs, at least for the 30k family (Sanchez-Navarro and Bol, 2001; Sanchez-Navarro et al., 2006). In vitro transcripts from these heterologous constructions plus the AMV wt, were mechanically inoculated in transgenic $N$. tabacum plants constitutively expressing the $\mathrm{P} 1$ and $\mathrm{P} 2$ sub-units of the viral replicase (P12 plants), to evaluate the cell-to-cell movement. Only single fluorescent cells were observed on P12 leaves (Figures 6Ac,d,f,g) by AMV RNA3 derivatives expressing the dichorhavirus MPs, indicating the incompatibility of these proteins to complement the local AMV movement. P12 leaves inoculated with AMV transcripts expressing its MP255 and MP wt resulted in clear fluorescence infection foci at 2 days post inoculation, as expected (control, Figures 6Aa,b). Additionally, we inserted the $\mathrm{N}$ and $\mathrm{P}$ genes of both CiLV-N and OFV-citrus into the AMV cDNA3 clone, and the mix of transcripts (MP, N, and P) was co-inoculated in $\mathrm{P} 12$ leaves in all possible combinations: MP:A44 + N:A44 + P:A44, MP:A44 + N:A44 + Pstop, MP:A44 + Nstop + P:A44, MP:A44 + Nstop + Pstop, MPstop + N:A44 + P:A44, MPstop + N:A44 + Pstop, MPstop + Nstop + P:A44, MPstop + Nstop + Pstop. No infection foci were observed for all combinations, as shown by the representative images in Figures 6Ae,h.

To evaluate movement properties of dichorhavirus MPs based in a trans-movement approach, Agrobacterium cultures transformed with binary plasmid carrying the CiLV-N and OFVcitrus MPs were infiltrated in N. benthamiana leaves, and at 1 day post infiltration, they were mechanically inoculated with transcripts from the infectious TCV $\triangle 92$-sGFP mutant, which has a 92 nucleotide deletion that abolishes the expression of the TCV double gene block (p8 and p9) movement proteins (Li et al., 1998; Powers et al., 2008), exhibiting a movementdeficiency phenotype. Foci formation, not limited to three or five cells observed in the negative control (pMOG-Lep, 

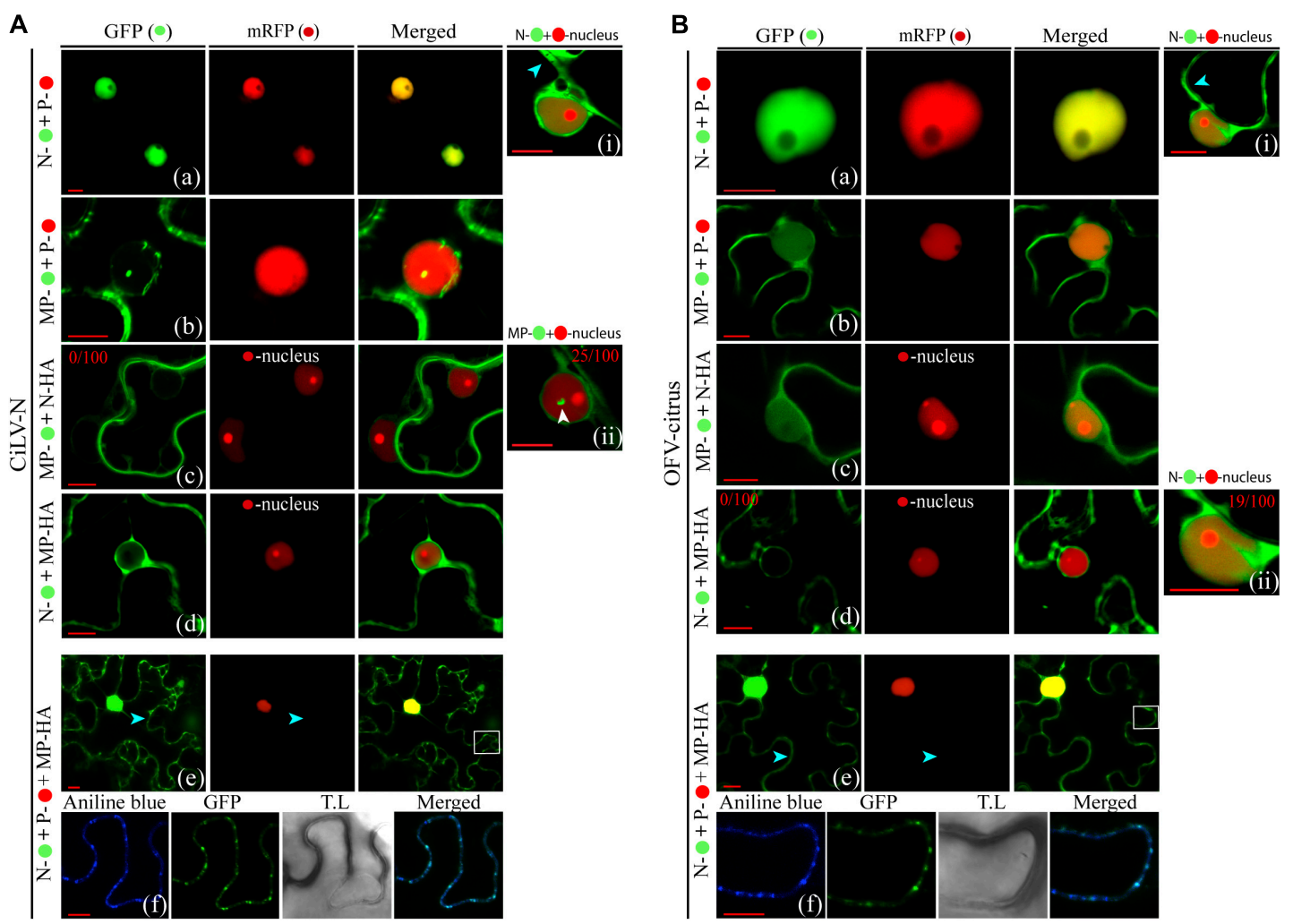

FIGURE 5 | Redistribution of the N protein from the N-P complex to the cell periphery and plasmodesmata upon co-expression with the MP. Confocal imagens of

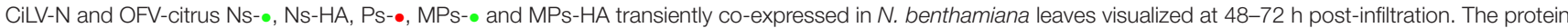

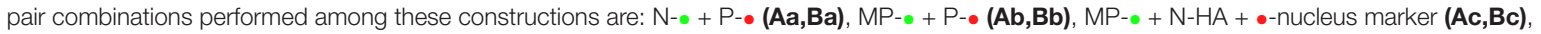

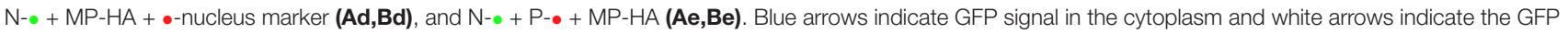
signal into the nucleus. The numbers at the top of $\mathbf{A i}, \mathbf{A c}, \mathbf{A i i}, \mathbf{B d}$, and $\mathbf{B i i}$ panels corresponds the number of nuclei visualized expressing the correspondent protein fused to GFP from 100 counted nuclei. White boxes correspond to high magnification to highlight callose deposits stained with aniline blue ( $\bullet$ ) along the cell periphery (Af,Bf). All images displayed are representative of at least three independent experiments. Bars correspond to $10 \mu \mathrm{m}$.

Figure 6Bb), were visualized by expression of cilevirus p32 movement protein (positive control, Figure 6Ba). On the other hand, the dichorhavirus MPs did not trans-complement the TCV $\triangle 92$-sGFP movement, showing only single fluorescent cells (Figures $\mathbf{6 B c}, \mathbf{d}$ ). Finally, we evaluated the movement properties of dichorhavirus MPs using a TMV infection construct (Canto and Palukaitis, 2002) lacking the MP gene (DsRedTMV- $\triangle \mathrm{MP}$ ). Individual fluorescent cells were visualized in $N$. benthamiana leaves inoculated with CiLV-N and OFVcitrus MPs (Figures 6Cc,d), instead of the cilevirus CiLV-C MP, which rescued the TMV movement generating large infection foci (Figure 6Ca). These results indicate that, unlike cilevirus MPs, the dichorhavirus MPs are not sufficient to rescue the cellto-cell movement of three different viruses, which have distinct viral transport mechanisms.

\section{The Ectopic Expression of the Dichorhavirus MPs Does Not Induce Tubular Structures on Protoplasts}

Next, we investigated whether the dichorhavirus MPs were capable of forming tubule structures on the surface of
N. benthamiana protoplasts. The MP:eGFP of CiLV-N and OFV-citrus were transiently expressed in $N$. benthamiana leaves by agroinfiltration. The protoplasts were prepared $24 \mathrm{~h}$ post infiltration (hpi), and GFP signals were visualized at $16 \mathrm{~h}$ after protoplasts purification. None of the dichorhavirus MPs were able to generate tubular structures, showing GFP signal accumulation as punctate structures at the cell periphery without tubule polymerization (Supplementary Figures 1a,b). The cilevirus CiLV-C2 MP induced the formation of tubular structures regardless of viral infection (positive control, Supplementary Figure 1f). In the present work, we observed that the OFV-citrus MP interacts with $\mathrm{P}$ and $\mathrm{N}$ and is able to recruit the $\mathrm{N}$ from the N-P complex to the plasmodesmata at the cell periphery. In order to evaluate if $\mathrm{N}$ or $\mathrm{P}$ proteins of OFV-citrus could be required for the MP tubule polymerization, we prepared protoplasts from $N$. benthamiana leaves transiently coexpressing the combinations $\mathrm{MP}+\mathrm{N}, \mathrm{MP}+\mathrm{P}$, and $\mathrm{MP}+\mathrm{N}+\mathrm{P}$. No tubular structures were visualized in any of the assayed protein combinations (Supplementary Figures 1c-e), further suggesting that dichorhavirus MPs are not tubule-forming proteins. 
A

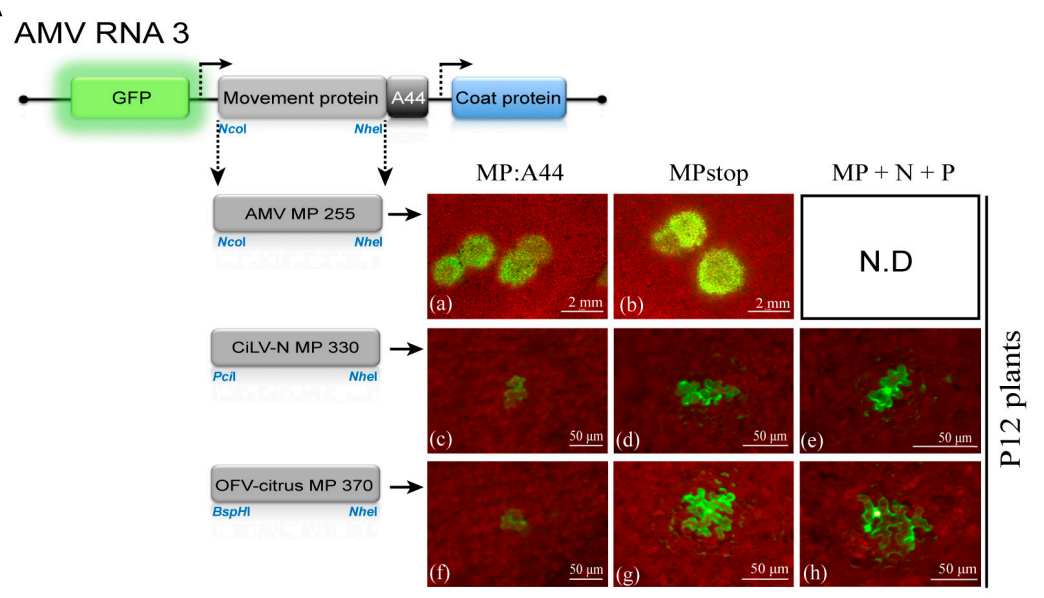

B

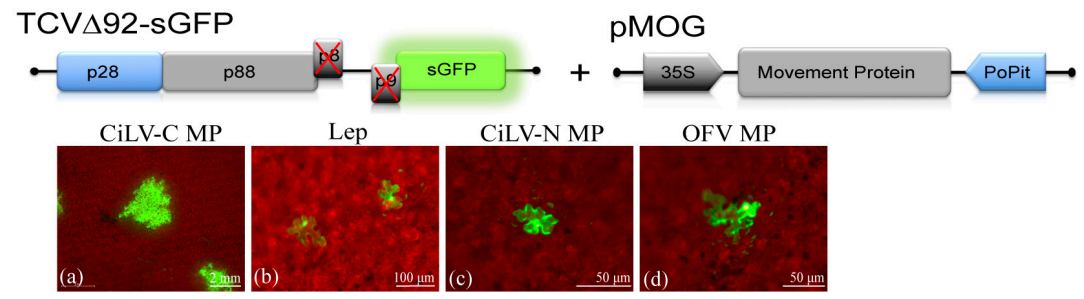

C

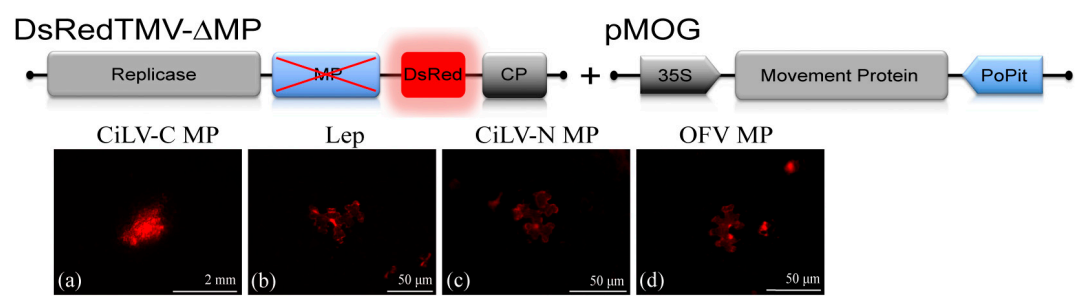

FIGURE 6 | The dichorhavirus MPs do not complement the cell-to-cell movement of the alfalfa mosaic virus (AMV), turnip crinkle virus (TCV) and tobacco mosaic virus (TMV) infectious clones. (A) Analysis of the cell-to-cell transport of the hybrid AMV RNA 3 in which its movement protein (MP) gene was exchanged with the corresponding genes (MPs) of citrus leprosis virus N (CiLV-N) and orchid fleck virus citrus strain (OFV-citrus). Individual GFP-cell foci are observed in P12 leaves inoculated with RNA 3 transcripts from pGFP/A255/CP derivatives carrying the heterologous MPs, fused with the C-terminal 44 residues of the AMV MP (A44) (c,f) or lacking the A44 (MPstop) (d,g). Infection foci are demonstrated for the AMV MP wild-type and the mutated version expressing the N-terminal 255 residues (positive control, a,b). Representative images of all combinations from co-inoculation of AMV RNA 3 transcripts carrying the N, P, and MP dichorhavirus genes are presented (e,h). The schematic representation shows the GFP/A255/CP AMV RNA 3, in which the open reading frames, represented by large boxes, correspond to the green fluorescent protein (GFP), the movement protein (MP), and the coat protein (CP). Short box corresponds to the C-terminal 44 amino acids of the AMV MP, meanwhile arrows represent subgenomic promoters. The numbers after the viral acronym represent the total amino acid residues of the corresponding MP. The Ncol, BspHI, Pcil, and Nhel restriction sites used for insertions of the MPs are indicated. White bars correspond to $50 \mu \mathrm{m}-2 \mathrm{~mm}$. Each infection foci image is representative of the inoculation of three leaves per plant and two plants inoculated for each chimeric AMV construct. ND, non-determined. (B) TCV assay based on the complementation of the movement-deficiency phenotype of a TCV MP mutant (TCV $\Delta 92$-sGFP). Three N. benthamiana leaves per plant were infiltrated with pMOG800 constructs carrying CiLV-C MP (a) (positive control) and MPs of CiLV-N (c) and OFV-citrus (d) or pMOG-Lep (b) as negative control. Infectious RNA transcript of the TCV $\Delta$ 92-sGFP construct was mechanically inoculated 1 day post agroinfiltration. Cell-to-cell movement was evaluated at 3 days post inoculation. Viral movement complementation is visualized for CiLV-C MP expression (a); meanwhile, only individual foci-cells are visualized for the leaves inoculated with the constructions expressing the dichorhavirus MPs (c,d). The schematic representations show: (1) the TCV RNA, in which the open reading frames are represented by the boxes. The p28 (blue box) and p88 (gray) code for replication proteins. The p8 and p9 encode movement proteins (black box) and the green fluorescent protein (GFP) is represented in the place of the viral coat protein. An X in the p8 and p9 indicates protein deletion. (2) pMOG expression cassette used for the ectopic expression of the MPs indicated. The genes were cloned between CaMV constitutive $35 \mathrm{~S}$ promoter (black box) and potato proteinase inhibitor terminator (PoPit, blue box). White bars correspond to $50 \mu \mathrm{m}-2 \mathrm{~mm}$. (C) TMV trans-complementation assay based on a TMV MP defective mutant expressing the red fluorescent protein (DsRed) (DsRedTMV- $\triangle \mathrm{MP}$ ). N. benthamiana leaves (three per plant) were infiltrated with an agrobacterial culture containing the binary pMOG constructs carrying CiLV-C MP (a), CiLV-N MP (c), OFV-citrus MP (d), or pMOG-Lep (b) as negative control. At 1 day post agroinfiltration, all infiltrated leaves were inoculated with DsRedTMV- $\Delta$ MP derived transcripts. The schematic representations show the PMOG cassette above described and the DsRedTMV- $\triangle M P$ RNA, in which the ORFs are represented by boxes corresponding to replicase (gray box), deleted MP (blue box), DsRed (red box), and the capsid protein (CP, gray box). White bars correspond to $50 \mu \mathrm{m}-2 \mathrm{~mm}$. 


\section{Revealing a Broad Permissibility of in vivo Interactions Between Proteins of Distinct BTVs}

Mixed infection of distinct BTVs and mutual mite colonization in citrus plants has been reported for the citrus leprosis pathosystem (Roy et al., 2015a; Beltran-Beltran et al., 2020). Therefore, we analyzed by BiFC assay, whether the viral movement components, suggested here for dichorhaviruses and previously characterized for cileviruses (Leastro et al., unpublished), could perform heterologous interactions. Negative controls for each specific interaction corresponded to the expression of the viral proteins tested in combination with Cyt or ER BiFC vectors, and a representative image corresponding to all experimental negative controls is presented in Figure 7E. As additional control for intra- and inter-association analyses, we expressed the CiLV-C MP with the cognate p24 protein (putative matrix protein) or with the $\mathrm{CP}$ and $\mathrm{N}$ proteins from viruses belonging to the genera Orthotospovirus and Alfamovirus (intra-association: CiLV-C p24 vs. CiLV-C MP, inter-association: AMV CP vs. CiLV-C MP and TSWV N vs. CiLV-C MP) in all cases resulting in the absence of fluorescence (Figure 7E), as previously demonstrated (Leastro et al., 2018, unpublished). All protein pair combinations performed in these assays are shown in Table 3. The BiFC image is representative of all protein pair combinations. The homologous and heterologous interactions for the capsid protein (p29) and MP of CiLVC were previously reported (Leastro et al., 2018). Here, we extended this understanding for CiLV-C2, another member of the genus Cilevirus. The BiFC assay suggests that CiLV-C2 p29 was able to form dimer structures in epidermal cells of N. benthamiana (Figure 7Ai). Similarly to what was observed for CiLV-C MP (Leastro et al., 2018), the CiLV-C2 MP was unable to dimerize (Figure 7Aii). The analysis of the CiLV-C2 p29-MP interaction showed a clear fluorescence reconstitution throughout the cytoplasm (Figure 7B), as recently reported for CiLV-C (Leastro et al., 2018).

Next, we tested the inter-protein association between different CL-associated cileviruses (CiLV-C vs. CiLV-C2) and dichorhaviruses (OFV-citrus vs. CiLV-N) proteins. For the cileviruses, the reconstituted fluorescence suggesting positive in vivo interaction was observed for the combinations: CiLV-C p29 vs. CiLV-C2 p29, CiLV-C p29 vs. CiLV-C2 MP, and CiLV-C2 p29 vs. CiLV-C MP (Figures 7Civ,vi,vii). No fluorescence was observed for the CiLV-C MP vs. CiLV-C2 MP combination (Figure 7Cv). For dichorhaviruses, fluorescence signal was observed in the CiLV-N N vs. OFV-citrus N, CiLV-N MP vs. OFVcitrus MP, and OFV-citrus $\mathrm{N}$ vs. CiLV-N MP combinations (Figures 7Cviii,ix,xi). On the other hand, no fluorescence signal was visualized in the CiLV-N N vs. OFV-citrus MP combination (Figure 7Cx).

Finally, we analyzed the interaction (inter-association) between proteins from viruses belonging to different genera (CiLV-C2 vs. OFV-citrus). Positive fluorescence signal was visualized for CiLV-C2 MP vs. OFV-citrus MP, CiLV-C2 p29 vs. OFV-citrus $\mathrm{N}$, and CiLV-C2 p29 vs. OFV-citrus MP combinations (Figures 7Dxii,xiii,xiv). No fluorescence was visualized for CiLV-C2 MP vs. OFV-citrus $\mathrm{N}$ combination (Figure 7Dxv). All BiFC suggesting interaction and subcelullar results obtained with the different dichorhaviruses and cileviruses proteins were used to generate a diagrammatic map of in vivo protein interactions and subcellular localizations for all of them (Figure 8).

\section{DISCUSSION}

In this report, we explored in detail different aspects related to the movement mechanism of dichorhaviruses by analyzing biological properties of the MP, N, and P proteins from viruses belonging to two different species. The analyses included membrane topology, subcellular localization, and in vivo protein-protein interaction between them but also with the capsid and movement proteins from distinct citrus leprosis-associated cileviruses.

The membrane fractionation analysis revealed that the MPs of two dichorhaviruses are membrane proteins strongly and physically associated to the cell membrane. This finding, together with the topology observed in the BiFC results, allows us to propose a topological model for the dichorhavirus MPs, in which the MPs are associated to membranes, but probably not integrally associated, with the full-length molecule oriented toward the cytoplasmic face of the biological membrane (see Figures 2Bxii, $\mathbf{C x x}$ ), and when present within the nucleus, located at the inner nuclear membrane. The capability to associate with cell membranes and topology reported here is in agreement with the pattern reported for different movement proteins of other negative and positive plant viruses belonging to the $30 \mathrm{~K}$ superfamily, including the MPs of the evolutionary related betanucleorhabdovirus SYNV and the cytorhabdovirus tomato yellow mottle-associated virus (TYMaV) (Melcher, 2000; Martínez-Gil et al., 2009; Genovés et al., 2011; Peiro et al., 2014b; Leastro et al., 2015; Zhou et al., 2019). However, since the dichorhavirus MPs do not belong to the $30 \mathrm{~K}$ superfamily (OFV and CiLV-N MP genes encode 41.7 and $36.6 \mathrm{kDa}$ proteins, which show no homology with the $30 \mathrm{~K} \mathrm{MPs}$ ), our data indicate that this topology is not only restricted to movement proteins belonging to that family. Moreover, it further strengthens the hypothesis that association between movement proteins with host membranes seems to be an essential factor for plant virus transport.

Both $\mathrm{N}$ proteins localized mainly in the cytoplasm, in the absence of other viral components. Similar subcellular localization has been reported for the OFV (orchid strain) $\mathrm{N}$ protein (Kondo et al., 2013). However, we observed the presence of CiLV-N and OFV-citrus $\mathrm{N}$ proteins in the nucleus, similarly to what was reported for the dichorhavirus coffee ringspot virus (CoRSV) (Ramalho et al., 2014), but not for the OFV orchid strain. For the latter, it was proposed that the nuclear localization of the $\mathrm{N}$ protein occurred through its interaction with the P protein, which possesses a nuclear localization signal (NLS) (Kondo et al., 2013). Here, we observed that, in the absence of the cognate $\mathrm{P}$ protein, both CiLV-N and OFVcitrus $\mathrm{N}$ proteins localize in the nucleus. Also, we observed that neither $\mathrm{N}$ proteins exhibit the NLS predicted domains (cNLS 
A

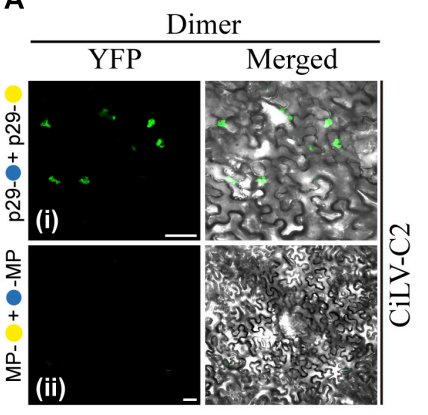

B

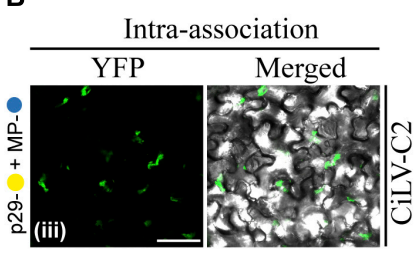

E

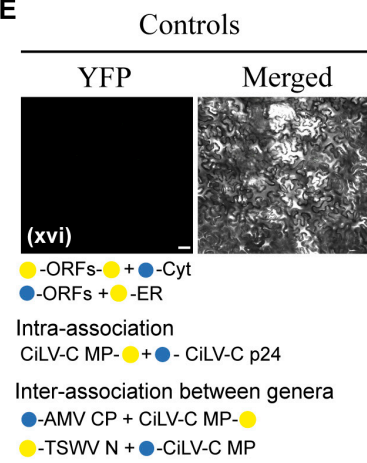

C

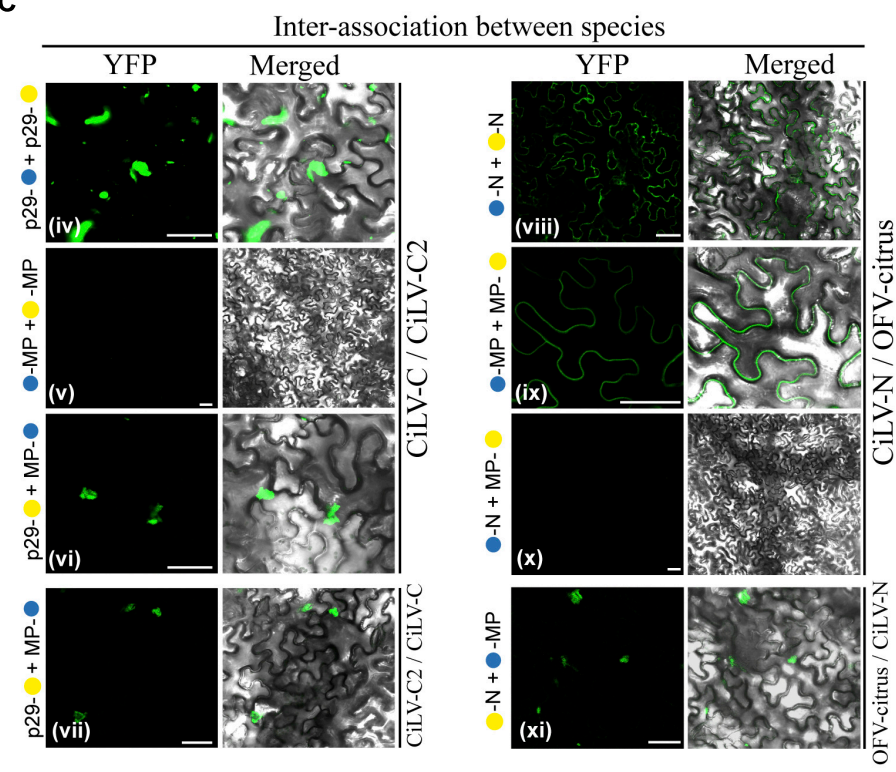

D

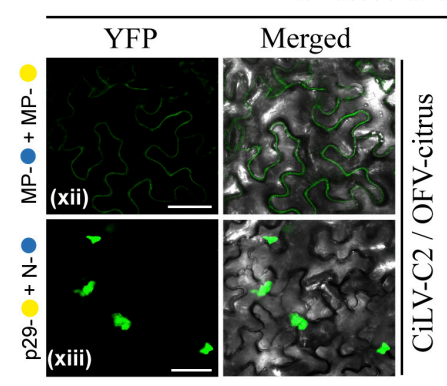

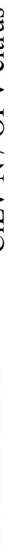

\section{.}

. 


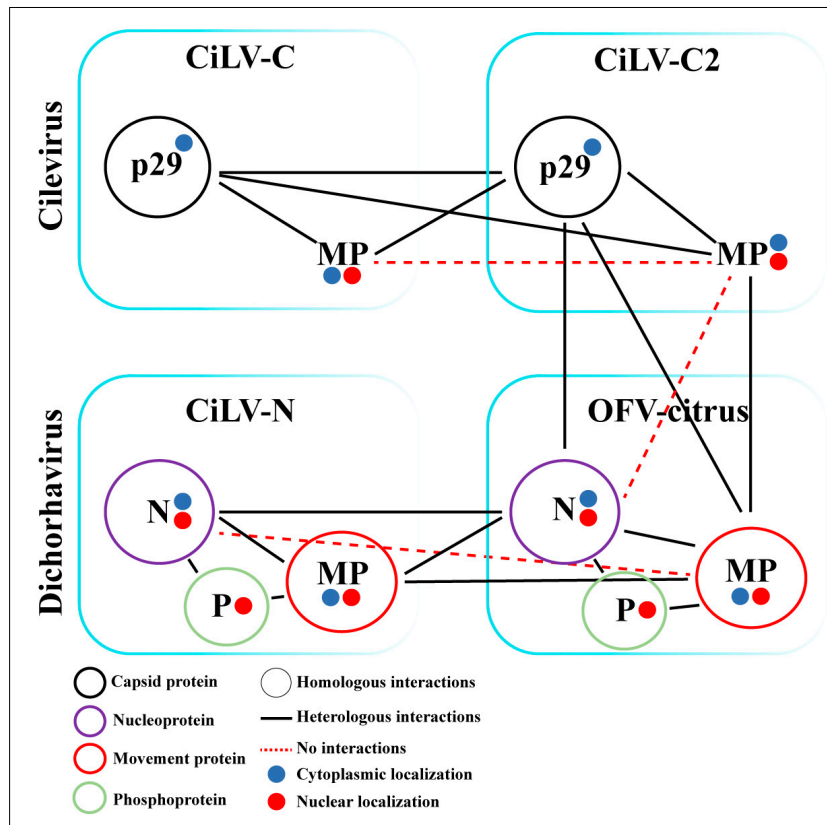

FIGURE $\mathbf{8}$ | Schematic diagram of the suggested viral protein interaction and localization maps for the cileviruses (CiLV-C and CiLV-C2) and dichorhaviruses (CiLV-N and OFV-citrus) indicated proteins. The scheme indicates the suggested dimeric protein interactions as well as heterologous interactions between proteins of viral species of the same genus and between different genera associated with the citrus leprosis photosystem. Self-interactions are indicated by a color circle specific to each protein. The circles filled with blue or red indicate the cytoplasmatic or nuclear protein localization, respectively. Circularized acronyms indicate positive homologous interactions. Black lines indicate positive heterologous interactions, while red dotted lines indicate lack of positive interaction.

cytorhabdovirus (LNYV), alfalfa dwarf cytorhabdovirus (ADV), and SYNV betanucleorhabdovirus (Goodin et al., 2002, 2007; Martin et al., 2012; Bejerman et al., 2015; Zhou et al., 2019). For the LNYV MP (4b protein), its nuclear localization was supported by the presence of a predicted NLS domain, whereas no canonical NLS was predicted for ADV MP (P3 protein). Using a cNLS Mapper software, we could not identify NLS domains for either CiLV-N or OFV-citrus MPs (data not shown).

A previous study demonstrated that the CoRSV MP was unable to interact with other CoRSV-encoded proteins (Ramalho et al., 2014). Here, we have demonstrated that both CiLV-N and $\mathrm{OFV}$-citrus MPs were able to interact in vivo with their cognate $\mathrm{N}$ and $\mathrm{P}$ proteins. The $\mathrm{MP}(\mathrm{P} 3$ protein)- $\mathrm{P}$ interaction in vivo has also been reported for the cytorhabdovirus ADV (Bejerman et al., 2015). In that study, the authors also observed a partial relocalization of the MP, from the cell periphery to the nucleus, when both MP and P proteins were co-expressed. For CiLV-N, the MP-P complex obtained from BiFC analysis was distributed into the nuclei and at the cell periphery. The observation that the CiLV-N P protein is exclusively detected in the nucleus, in the absence of other viral proteins, indicates that the MP may recruit the $\mathrm{P}$ protein from the nucleus to the cell periphery, opening the possibility that the $\mathrm{P}$ protein could be implicated in the virus movement mechanism. In contrast to CiLV-N, the OFVcitrus MP-P complex was visualized exclusively into the nucleus, suggesting multiple functions for this MP. The CiLV-N N-MP complex formed in BiFC analysis was mostly distributed in the cytoplasm, where the $\mathrm{N}$ protein was able to relocalize the MP from the nucleus in co-expression analysis, indicating that the $\mathrm{N}$ protein may also assist the MP export. On the other hand, for OFV-citrus, the localization of the N-MP complex occurred mostly in the nucleus. However, co-expression analysis revealed that the $\mathrm{N}$ protein was redirected exclusively to the cell cytoplasm. Taken together with the localization results presented for the MP-P complex, our findings suggest that the CiLV-N MP may recruit both $\mathrm{N}$ and $\mathrm{P}$ for the movement, whereas the OFV-citrus $\mathrm{P}$ and $\mathrm{N}$ seem to recruit the MP to the nucleus, but remarkably, the opposite is also observed with the $\mathrm{N}$ being exported to the cytoplasm. This observation clearly demonstrates the use of different infection mechanisms for these dichorhaviruses, and more importantly, the existence of a dynamic interaction complex formed between the MP with the cognate nucleocapsid (N-P) proteins, strongly suggesting that, for dichorhaviruses, the nucleocapsid could play a role in viral movement mechanism, as observed for other plant viruses (Chapman et al., 1992; Forster et al., 1992; Nagano et al., 2001). A common property observed for both viruses was the redistribution of a portion of the $\mathrm{N}$ protein from the nucleus to the cytoplasm and to plasmodesma structures upon co-expression of the three MP, N, and P proteins (Figure 5). A similar feature has been recently reported for the phylogenetically related betanucleorhabdovirus SYNV, in which the viral MP (sc4) directed a portion of the N-P complex from nuclear sites of replication to the cell periphery, co-localizing partially with PD (Zhou et al., 2019). For both CiLV-N and OFVcitrus, we do not rule out the possibility that a reduced portion of the N-P complex could be redirected to the cell periphery in the presence of the MP mediated through the MP-P interaction, especially for CiLV-N. Further analyses will be addressed to confirm this hypothesis.

Our findings reveal that dichorhavirus MPs do not display cross-movement complementation with distinct $(+)$ RNA viruses, suggesting either that these MPs mediate virus transport with a mechanism distinct from those viruses used in the transport complementation assay or the requirement of specific interactions and/or proteins playing a role in virus transport. For plant rhabdoviruses and others (-)ssRNA viruses, their MPs were able to rescue the cell-to-cell movement of potexvirus, tobamovirus, or alfamovirus defective-movement mutants (Huang et al., 2005; Peiro et al., 2014a; Mann et al., 2016; Leastro et al., 2017b; Zhou et al., 2019). On the other hand, defective nucleo- and cytorhabdovirus movement mutants were rescued only by their cognate MPs (Zhou et al., 2019). Thus, we speculate that the movement mechanism mediated by the dichorhavirus MP could be specific, requiring cognate viral proteins as shown for other plant rhabdoviruses. Based on our findings on redistribution and plasmodesmata localization of the nucleocapsids, it is tempting to hypothesize that the cognate N-P complex could be the specific viral accessory factor needed to ensure virus spread. In this sense, we tested the co-expression of N, P, and MP in AMV context, which was unsuccessful. This 
observation further suggests that dichorhavirus MPs could have a strong specificity requiring cognate factors or cis elements, in natural infection context, which cannot be reproduced in heterologous systems. The incapacity of their MPs to rescue the movement of these classical virus systems opens the possibility of the existence of a viral movement mechanism, mediated by dichorhavirus MPs, different from those known so far. An infectious clone-based study model for dichorhavirus would allow investigating in detail its movement mechanism.

The dichorhavirus MPs transiently expressed on protoplasts of $N$. benthamiana did not result in tubule formation either alone or by the co-expression with the cognate nucleocapsid proteins, suggesting that these MPs are non-tubule forming. This is in agreement with the viral non-tubule guided movement mechanism, where the MPs modify plasmodesmatal size exclusion limit without the tubule polymerization (Wolf et al., 1989). Whether dichorhavirus MPs can form tubule structures on the natural context of viral infection remains to be addressed.

Mixed infection favors genetic rearrangement of viral species and may also potentiate the process of viral infection (Roossinck, 1997; Leastro et al., 2015; Moreno and LopezMoya, 2020). Therefore, we explored the association between movement components of dichorhaviruses (MP, N, and $\mathrm{P}$ proteins) and cileviruses (MP and p29 proteins). Interactions between movement viral components have been noticed for distinct orthotospoviruses (Leastro et al., 2015), revealing broad compatibility between MPs and Ns from four tested viruses. Here, the in vivo BiFC analyses suggested positive interactions among almost all CP-MP, N-MP, and MP-MP combinations from different BTVs. No interactions were identified only for interassociation analyses between cilevirus MPs and between CiLV-N $\mathrm{N}$ and OFV MP. Although positive interactions between viral MPs with heterologous capsid proteins have also been noticed for other viral genera (Leastro et al., 2015), this aspect seems not to be a rule for plant viruses, i.e., the MPs of AMV, brome mosaic virus (BMV), cucumber mosaic virus (CMV), and papaya ringspot virus (PRSV) interact with their cognate but not with heterologous CPs (Nagano et al., 1997; Takeda et al., 2004; Sanchez-Navarro et al., 2006; Aparicio et al., 2010).

Regarding the dimer analysis of the MP (for both genera), p29 (for cilevirus), and $\mathrm{N}$ (for dichorhavirus) proteins, the only negative interaction noticed was for CiLV-C2 MP, which is inconsistent with the recent observation showing the capacity of this protein to polymerize, forming tubular structures on the protoplasts surface (Leastro et al., unpublished). We speculate that dimerization of this MP could be incompatible with the fusion of the YFP fragment or with the right orientation of the two YFP fragments.

The BiFC analyses using proteins from distinct BTV (CiLV-C2 vs. OFV-citrus), also suggested a broad compatibility interaction among MPs, CPs, and Ns proteins. The permissibility reported here agrees with the report of mutual mite colonization and mixed CiLV-C2 and OFV-citrus infection in the same lesion (Roy et al., 2015a); although, in nature, the chance of CL-associated viruses to interact with each other can be considered very low, since they do not spread systemically in their hosts, remaining localized in the lesions they induce (Freitas-Astua et al., 2018).
Among all the in vivo protein-protein interactions evaluated for CiLV-C2 and OFV-citrus, the only negative interaction was observed between CiLV-C2 MP and OFV-citrus N, although we have observed interaction between OFV-citrus MP and CiLV-C2 CP, suggesting that the dichorhavirus MP could assist the transport of both cognate nucleocapsid and heterologous capsid proteins in the mixed infection process. In this sense, we have observed that the dichorhavirus MP redirects the cognate $\mathrm{N}$ from the nucleus to the plasmodesma at the cell periphery. However, to determine whether this capability could be extended for the transport of the capsid protein of a nongenetically related virus, further tests are required. Considering the mixed infection between species in the CL pathosystem, heterologous interactions between viral proteins of distinct species could represent a potential to generate synergism. Further analysis will be addressed to confirm the putative synergism, based on heterologous protein-protein interactions, in mixed infections of BTV.

\section{DATA AVAILABILITY STATEMENT}

All datasets generated for this study are included in the article/Supplementary Material, further inquiries can be directed to the corresponding authors.

\section{AUTHOR CONTRIBUTIONS}

ML and JS-N conceived and designed the experiments and analyzed and interpreted the data. ML performed the experiments and wrote the original draft. ML, JF-A, EK, VP, and JS-N contributed with reagents, materials, and tools, revised and edited the manuscript. All authors contributed to the article and approved the submitted version.

\section{FUNDING}

This work was supported by the Fundação de Amparo à Pesquisa do Estado de São Paulo (FAPESP), proc. 2014/08459, 2015/10249-1, 2017/50222-0, and 2017/19898-8. This work was also supported by grant BIO2017-88321-R from the Spanish Dirección General de Investigación Científica y Técnica (DGICYT) and the Prometeo Program GV2015/010 from the Generalitat Valenciana.

\section{ACKNOWLEDGMENTS}

We are grateful to Ms. Lorena Corachán for her excellent technical support and to Drs. G. Otero-Colina (Colegio de Postgraduados, Texcoco, Mexico) and W. Turizo-Álvarez (Universidad Nacional de Colombia, Bogotá, Colombia) for kindly providing OFV-citrus and CiLV-C2 samples used in this work. 


\section{SUPPLEMENTARY MATERIAL}

The Supplementary Material for this article can be found online at: https://www.frontiersin.org/articles/10.3389/fmicb. 2020.571807/full\#supplementary-material

Supplementary Figure 1 | The MPs of dichorhaviruses do not induce tubular structures on protoplast. Analysis of tubule formation of $N$. benthamiana protoplasts transiently expressing the MP genes of CiLV-N (a), OFV-citrus (b), and CiLV-C2 (f, positive control) fused at their C-termini with eGFP (•). Three infiltrated

\section{REFERENCES}

Aparicio, F., Pallas, V., and Sanchez-Navarro, J. (2010). Implication of the C terminus of the Prunus necrotic ringspot virus movement protein in cell-tocell transport and in its interaction with the coat protein. J. Gen. Virol. 91, 1865-1870. doi: 10.1099/vir.0.019950-0

Aparicio, F., Sanchez-Navarro, J. A., and Pallas, V. (2006). In vitro and in vivo mapping of the Prunus necrotic ringspot virus coat protein C-terminal dimerization domain by bimolecular fluorescence complementation. J. Gen. Virol. 87, 1745-1750. doi: 10.1099/vir.0.81696-0

Bastianel, M., Novelli, V., Kitajima, E. W., Bassanezi, R., Machado, M. A., and Freitas-Astúa, J. (2010). Citrus leprosis: centennial of an unusual mite virus phatosystem. Plant Dis. 94, 284-292. doi: 10.1094/pdis-94-3-0284

Bejerman, N., Giolitti, F., De Breuil, S., Trucco, V., Nome, C., Lenardon, S., et al (2015). Complete genome sequence and integrated protein localization and interaction map for alfalfa dwarf virus, which combines properties of both cytoplasmic and nuclear plant rhabdoviruses. Virology 483, 275-283. doi: 10 1016/j.virol.2015.05.001

Beltran-Beltran, A. K., Santillan-Galicia, M. T., Guzman-Franco, A. W., TelizOrtiz, D., Gutierrez-Espinoza, M. A., Romero-Rosales, F., et al. (2020) Incidence of Citrus leprosis virus $\mathrm{C}$ and orchid fleck dichorhavirus citrus strain in mites of the Genus Brevipalpus in Mexico. J. Econ. Entomol. 113, 1576-1581. doi: $10.1093 /$ jee/toaa007

Bordier, C. (1981). Phase separation of integral membrane proteins in Triton X-114 solution. J. Biol. Chem. 256, 1604-1607.

Brown, J. K., Idris, A. M., Alteri, C., and Stenger, D. C. (2002). Emergence of a new cucurbit-infecting begomovirus species capable of forming viable reassortants with related viruses in the squash leaf curl virus cluster. Phytopathology 92 734-742. doi: 10.1094/phyto.2002.92.7.734

Canto, T., and Palukaitis, P. (2002). Novel N gene-associated, temperatureindependent resistance to the movement of tobacco mosaic virus vectors neutralized by a cucumber mosaic virus RNA1 transgene. J. Virol. 76, 1290812916. doi: 10.1128/jvi.76.24.12908-12916.2002

Chabi-Jesus, C., Ramos-Gonzalez, P. L., Tassi, A. D., Guerra-Peraza, O., Kitajima, E. W., Harakava, R., et al. (2018). Identification and characterization of citrus chlorotic spot virus, a new dichorhavirus associated with citrus leprosis-like symptoms. Plant Dis. 102, 1588-1598. doi: 10.1094/pdis-09-17-1425-re

Chapman, S., Hills, G., Watts, J., and Baulcombe, D. (1992). Mutational analysis of the coat protein gene of potato virus X: effects on virion morphology and viral pathogenicity. Virology 191, 223-230. doi: 10.1016/0042-6822(92)90183-p

Cook, G., Kirkman, W., Clase, R., Steyn, C., Basson, E., Fourie, P. H., et al. (2019). Orchid fleck virus associated with the first case of citrus leprosis- $\mathrm{N}$ in South Africa. Eur. J. Plant Pathol. 155, 1373-1379. doi: 10.1007/s10658-01901854-4

Cruz-Jaramillo, J. L., Ruiz-Medrano, R., Rojas-Morales, L., Lopez-Buenfil, J. A., Morales-Galvan, O., Chavarin-Palacio, C., et al. (2014). Characterization of a proposed dichorhavirus associated with the citrus leprosis disease and analysis of the host response. Viruses 6, 2602-2622. doi: 10.3390/v6072602

Deng, M., Bragg, J. N., Ruzin, S., Schichnes, D., King, D., Goodin, M. M., et al. (2007). Role of the sonchus yellow net virus N protein in formation of nuclear viroplasms. J. Virol. 81, 5362-5374. doi: 10.1128/jvi.02349-06

Dietzgen, R. G., Bejerman, N. E., Goodin, M. M., Higgins, C. M., Huot, O. B., Kondo, H., et al. (2020). Diversity and epidemiology of plant rhabdoviruses. Virus Res. 281:197942. doi: 10.1016/j.virusres.2020.197942 leaves per construct were used for protoplasts isolation. Protoplasts were purified after one day post-infiltration and the fluorescence GFP signal was captured $16 \mathrm{~h}$ post-protoplasts purification with a Zeiss LSM 780 confocal laser-scanning microscope. The green (GFP), transmitted light (TL) channels and merged images are shown. Each image-frame expressing GFP represents the visualization of several protoplasts (about 15 to 20) per assay for each MP protein analyzed. Protoplast preparations from co-infiltration of the OFV-citrusMP:eGFP with cognates $\mathrm{N}$ and $\mathrm{P}$ carrying a $\mathrm{C}$-terminal $\mathrm{HA}$ tag is presented. Tubule formation is observed from expression of the CiLV-C2 MP (f). GFP signal in punctate structures on surface of protoplast is visualized for all other (a-e) dichorhaviruses proteins expressed (c). Red bars correspond to $10 \mu \mathrm{m}$.

Dietzgen, R. G., Freitas-Astua, J., Chabi-Jesus, C., Ramos-Gonzalez, P. L., Goodin, M. M., Kondo, H., et al. (2018). Dichorhaviruses in their host plants and mite vectors. Adv. Virus Res. 102, 119-148. doi: 10.1016/bs.aivir.2018.06.001

Forster, R. L., Beck, D. L., Guilford, P. J., Voot, D. M., Van Dolleweerd, C. J., and Andersen, M. T. (1992). The coat protein of white clover mosaic potexvirus has a role in facilitating cell-to-cell transport in plants. Virology 191, 480-484 doi: 10.1016/0042-6822(92)90215-b

Freitas-Astúa, J., Dietzgen, R. G., Walker, P. J., Blasdell, K. R., and Breyta, E. A. (2019). Split the Genus Nucleorhabdovirus, Creating Three New Genera (Alphanucleorhabdovirus, Betanucleorhabdovirus and Gammanucleorhabdovirus) Comprising Sixteen Species, Including Six New Species, in the Family Rhabdoviridae. Available online at: https://ictv.global/ICTV/proposals/2019.031M.zip (accessed on 18 May 2020).

Freitas-Astúa, J., Moreira, L., Rivera, C., and Rodriguez, C. M. (2002). First report of Orchid fleck virus in Costa Rica. Plant Dis. 86:1402. doi: 10.1094/pdis.2002. 86.12.1402d

Freitas-Astua, J., Ramos-Gonzalez, P. L., Arena, G. D., Tassi, A. D., and Kitajima, E. W. (2018). Brevipalpus-transmitted viruses: parallelism beyond a common vector or convergent evolution of distantly related pathogens? Curr. Opin. Virol. 33, 66-73. doi: 10.1016/j.coviro.2018.07.010

Genovés, A., Pallás, V., and Navarro, J. A. (2011). Contribution of topology determinants of a viral movement protein to its membrane association, intracellular traffic, and viral cell-to-cell movement. J. Virol. 85, 7797-7809. doi: $10.1128 /$ jvi.02465-10

Ghosh, D., Brooks, R. E., Wang, R., Lesnaw, J., and Goodin, M. M. (2008). Cloning and subcellular localization of the phosphoprotein and nucleocapsid proteins of Potato yellow dwarf virus, type species of the genus Nucleorhabdovirus. Virus Res. 135, 26-35. doi: 10.1016/j.virusres.2008.02.003

Gibbs, A., Mackenzie, A., Blanchfield, A., Cross, P., Wilson, C., Kitajima, E. W., et al. (2000). Viruses of orchids in Australia: their identification, biology and control. Aust. Orchid. Rev. 65, 10-21.

Goodin, M. M., Austin, J., Tobias, R., Fujita, M., Morales, C., and Jackson, A. O. (2001). Interactions and nuclear import of the $\mathrm{N}$ and $\mathrm{P}$ proteins of sonchus yellow net virus, a plant nucleorhabdovirus. J. Virol. 75, 9393-9406. doi: 10. 1128/jvi.75.19.9393-9406.2001

Goodin, M. M., Chakrabarty, R., Yelton, S., Martin, K., Clark, A., and Brooks, R. (2007). Membrane and protein dynamics in live plant nuclei infected with Sonchus yellow net virus, a plant-adapted rhabdovirus. J. Gen. Virol. 88, 1810 1820. doi: 10.1099/vir.0.82698-0

Goodin, M. M., Dietzgen, R. G., Schichnes, D., Ruzin, S., and Jackson, A. O. (2002) pGD vectors: versatile tools for the expression of green and red fluorescent protein fusions in agroinfiltrated plant leaves. Plant J. 31, 375-383. doi: 10. 1046/j.1365-313x.2002.01360.x

Hofmann, C., Niehl, A., Sambade, A., Steinmetz, A., and Heinlein, M. (2009). Inhibition of tobacco mosaic virus movement by expression of an actin-binding protein. Plant Physiol. 149, 1810-1823. doi: 10.1104/pp.108.133827

Huang, Y. W., Geng, Y. F., Ying, X. B., Chen, X. Y., and Fang, R. X. (2005) Identification of a movement protein of rice yellow stunt rhabdovirus. J. Virol. 79, 2108-2114. doi: 10.1128/jvi.79.4.2108-2114.2005

Idris, A. M., and Brown, J. K. (2004). Cotton leaf crumple virus is a distinct western hemisphere begomovirus species with complex evolutionary relationships indicative of recombination and reassortment. Phytopathology 94, 1068-1074. doi: 10.1094/phyto.2004.94.10.1068 
Idris, A. M., Mills-Lujan, K., Martin, K., and Brown, J. K. (2008). Melon chlorotic leaf curl virus: characterization and differential reassortment with closest relatives reveal adaptive virulence in the squash leaf curl virus clade and host shifting by the host-restricted bean calico mosaic virus. J. Virol. 82, 1959-1967. doi: 10.1128/jvi.01992-07

Kang, S. H., Bak, A., Kim, O. K., and Folimonova, S. Y. (2015). Membrane association of a nonconserved viral protein confers virus ability to extend its host range. Virology 482, 208-217. doi: 10.1016/j.virol.2015.03.047

Kawakami, S., Watanabe, Y., and Beachy, R. N. (2004). Tobacco mosaic virus infection spreads cell to cell as intact replication complexes. Proc. Natl. Acad. Sci. U.S.A. 101, 6291-6296. doi: 10.1073/pnas.0401221101

Kondo, H., Chiba, S., Andika, I. B., Maruyama, K., Tamada, T., and Suzuki, N. (2013). Orchid fleck virus structural proteins $\mathrm{N}$ and $\mathrm{P}$ form intranuclear viroplasm-like structures in the absence of viral infection. J. Virol. 87, 74237434. doi: 10.1128/jvi.00270-13

Kondo, H., Maeda, T., and Tamada, T. (2003). Orchid fleck virus: Brevipalpus californicus mite transmission, biological properties and genome structure. Exp. Appl. Acarol. 30, 215-223. doi: 10.1023/b:appa.0000006550.88615.10

Kondo, H., Maruyama, K., Chiba, S., Andika, I. B., and Suzuki, N. (2014). Transcriptional mapping of the messenger and leader RNAs of orchid fleck virus, a bisegmented negative-strand RNA virus. Virology 452-453, 166-174. doi: 10.1016/j.virol.2014.01.007

Leastro, M. O., Castro, D. Y. O., Freitas-Astua, J., Pallas, V., and Sánchez-Navarro, J. A. (2020). Citrus leprosis Virus C encodes three proteins with gene silencing suppression activity. Front. Microbiol. 11:1231. doi: 10.3389/fmicb.2020.01231

Leastro, M. O., De Oliveira, A. S., Pallas, V., Sanchez-Navarro, J. A., Kormelink, R., and Resende, R. O. (2017a). The NSm proteins of phylogenetically related tospoviruses trigger Sw-5b-mediated resistance dissociated of their cell-tocell movement function. Virus Res. 240, 25-34. doi: 10.1016/j.virusres.2017. 07.019

Leastro, M. O., Pallas, V., Resende, R. O., and Sanchez-Navarro, J. A. (2017b). The functional analysis of distinct tospovirus movement proteins (NSM) reveals different capabilities in tubule formation, cell-to-cell and systemic virus movement among the tospovirus species. Virus Res. 227, 57-68. doi: 10.1016/j. virusres.2016.09.023

Leastro, M. O., Kitajima, E. W., Silva, M. S., Resende, R. O., and FreitasAstua, J. (2018). Dissecting the subcellular localization, intracellular trafficking, interactions, membrane association, and topology of citrus leprosis Virus C proteins. Front. Plant Sci. 9:1299. doi: 10.3389/fpls.2018.01299

Leastro, M. O., Pallas, V., Resende, R. O., and Sanchez-Navarro, J. A. (2015). The movement proteins (NSm) of distinct tospoviruses peripherally associate with cellular membranes and interact with homologous and heterologous NSm and nucleocapsid proteins. Virology 478, 39-49. doi: 10.1016/j.virol.2015.01.031

Li, W. Z., Qu, F., and Morris, T. J. (1998). Cell-to-cell movement of turnip crinkle virus is controlled by two small open reading frames that function in trans. Virology 244, 405-416. doi: 10.1006/viro.1998.9125

Locali-Fabris, E. C., Freitas-Astúa, J., and Machado, M. A. (2012). "Genus Cilevirus," in Virus Taxonomy: Classification and Nomenclature of Viruses: Ninth Report of the International Committee on Taxonomy of Viruses, eds A. M. Q. King, M. J. Adams, E. B. Carstens, and E. J. Lefkowitz (San Diego, CA: Elsevier), 1139-1142.

Loesch-Fries, L. S., Halk, E. L., Nelson, S. E., and Krahn, K. J. (1985). Human leukocyte interferon does not inhibit alfalfa mosaic virus in protoplasts or tobacco tissue. Virology 143, 626-629. doi: 10.1016/0042-6822(85)90402-7

Mann, K. S., Bejerman, N., Johnson, K. N., and Dietzgen, R. G. (2016). Cytorhabdovirus P3 genes encode 30K-like cell-to-cell movement proteins. Virology 489, 20-33. doi: 10.1016/j.virol.2015.11.028

Martin, K. M., Dietzgen, R. G., Wang, R., and Goodin, M. M. (2012). Lettuce necrotic yellows cytorhabdovirus protein localization and interaction map, and comparison with nucleorhabdoviruses. J. Gen. Virol. 93, 906-914. doi: 10.1099/ vir.0.038034-0

Martínez-Gil, L., Sánchez-Navarro, J. A., Cruz, A., Pallás, V., Pérez-Gil, J., and Mingarro, I. (2009). Plant virus cell-to-cell movement is not dependent on the transmembrane disposition of its movement protein. J. Virol. 83, 5535-5543. doi: 10.1128/jvi.00393-09

Martinez-Perez, M., Navarro, J. A., Pallas, V., and Sanchez-Navarro, J. A. (2019). A sensitive and rapid RNA silencing suppressor activity assay based on alfalfa mosaic virus expression vector. Virus Res. 272:197733. doi: 10.1016/j.virusres. 2019.197733

Melcher, U. (2000). The '30K' superfamily of viral movement proteins. J. Gen. Virol. 81, 257-266. doi: 10.1099/0022-1317-81-1-257

Moreno, A. B., and Lopez-Moya, J. J. (2020). When viruses play team sports: mixed infections in plants. Phytopathology 110, 29-48. doi: 10.1094/phyto-07-190250-fi

Nagano, H., Mise, K., Furusawa, I., and Okuno, T. (2001). Conversion in the requirement of coat protein in cell-to-cell movement mediated by the cucumber mosaic virus movement protein. J. Virol. 75, 8045-8053. doi: 10.1128/jvi.75.17. 8045-8053.2001

Nagano, H., Okuno, T., Mise, K., and Furusawa, I. (1997). Deletion of the C-terminal 33 amino acids of cucumber mosaic virus movement protein enables a chimeric brome mosaic virus to move from cell to cell. J. Virol. 71, 2270-2276. doi: 10.1128/jvi.71.3.2270-2276.1997

Navarro, J. A., Sanchez-Navarro, J. A., and Pallas, V. (2019). Key checkpoints in the movement of plant viruses through the host. Adv. Virus Res. 104, 1-64. doi: 10.1016/bs.aivir.2019.05.001

Peiro, A., Canizares, M. C., Rubio, L., Lopez, C., Moriones, E., Aramburu, J., et al. (2014a). The movement protein (NSm) of Tomato spotted wilt virus is the avirulence determinant in the tomato $\mathrm{Sw}-5$ gene-based resistance. Mol. Plant Pathol. 15, 802-813. doi: 10.1111/mpp.12142

Peiro, A., Martinez-Gil, L., Tamborero, S., Pallas, V., Sanchez-Navarro, J. A., and Mingarro, I. (2014b). The Tobacco mosaic virus movement protein associates with but does not integrate into biological membranes. J. Virol. 88, 3016-3026. doi: 10.1128/jvi.03648-13

Peremyslov, V. V., Pan, Y. W., and Dolja, V. V. (2004). Movement protein of a closterovirus is a type III integral transmembrane protein localized to the endoplasmic reticulum. J. Virol. 78, 3704-3709. doi: 10.1128/jvi.78.7.37043709.2004

Petzold, H. (1971). Electron microscopy demonstration of a bacilliform virus in Dendrobium. J. Phytopathol. 70, 43-52. doi: 10.3354/dao027043

Pitzalis, N., and Heinlein, M. (2017). The roles of membranes and associated cytoskeleton in plant virus replication and cell-to-cell movement. J. Exp. Bot. 69, 117-132. doi: 10.1093/jxb/erx334

Powers, J. G., Sit, T. L., Qu, F., Morris, T. J., Kim, K. H., and Lommel, S. A. (2008). A versatile assay for the identification of RNA silencing suppressors based on complementation of viral movement. Mol. Plant Microbe Interact. 21, 879-890. doi: 10.1094/mpmi-21-7-0879

Quito-Avila, D. F., Freitas-Astúa, J., and Melzer, M. J. (2020). “Bluner-, Cile-, and Higreviruses (Kitaviridae)," in Reference Module in Life Sciences (Amsterdam: Elsevier), 1-5. doi: 10.1109/tmag.2013.2278570

Ramalho, T. O., Figueira, A. R., Sotero, A. J., Wang, R., Geraldino Duarte, P. S., Farman, M., et al. (2014). Characterization of coffee ringspot virus-Lavras: a model for an emerging threat to coffee production and quality. Virology 464-465, 385-396. doi: 10.1016/j.virol.2014.07.031

Ramos-Gonzalez, P. L., Chabi-Jesus, C., Guerra-Peraza, O., Tassi, A. D., Kitajima, E. W., Harakava, R., et al. (2017). Citrus leprosis virus N: a new dichorhavirus causing citrus leprosis disease. Phytopathology 107, 963-976. doi: 10.1094/ phyto-02-17-0042-r

Ritzenthaler, C., and Hofmann, C. (2007). "Tubule-guided movement of plant viruses," in Viral Transport in Plants, eds E. Waigmann and M. Heinlein (Berlin: Springer-Verlag), 63-83. doi: 10.1007/7089_2006_105

Roossinck, M. J. (1997). Mechanisms of plant virus evolution. Annu. Rev. Phytopathol. 35, 191-209.

Roy, A., Hartung, J. S., Schneider, W., Shao, J., Leon, G., Melzer, M. J., et al. (2015a). Role bending: complex relationships between viruses, hosts and vectors related to citrus leprosis, an emerging disease. Phytopathology 105, 1013-1025. doi: 10.1094/phyto-12-14-0375-fi

Roy, A., Stone, A. L., Shao, J., Otero-Colina, G., Wei, G., Choudhary, N., et al. (2015b). Identification and molecular characterization of nuclear citrus leprosis virus, a member of the proposed dichorhavirus genus infecting multiple citrus species in Mexico. Phytopathology 105, 564-575. doi: 10.1094/phyto-09-140245-r

Sambade, A., and Heinlein, M. (2009). Approaching the cellular mechanism that supports the intercellular spread of Tobacco mosaic virus. Plant Signal. Behav. 4, 35-38. doi: $10.4161 /$ psb.4.1.7253 
Sanchez-Navarro, J., Miglino, R., Ragozzino, A., and Bol, J. F. (2001). Engineering of alfalfa mosaic virus RNA 3 into an expression vector. Arch. Virol. 146, 923-939. doi: 10.1007/s007050170125

Sanchez-Navarro, J. A., and Bol, J. F. (2001). Role of the alfalfa mosaic virus movement protein and coat protein in virus transport. Mol. Plant Microbe Interact. 14, 1051-1062. doi: 10.1094/mpmi.2001.14.9.1051

Sanchez-Navarro, J. A., Carmen Herranz, M., and Pallas, V. (2006). Cell-to-cell movement of Alfalfa mosaic virus can be mediated by the movement proteins of Ilar-, bromo-, cucumo-, tobamo- and comoviruses and does not require virion formation. Virology 346, 66-73. doi: 10.1016/j.virol.2005.10.024

Sanchez-Velazquez, E. J., Santillan-Galicia, M. T., Novelli, V. M., Nunes, M. A., Mora-Aguilera, G., Valdez-Carrasco, J. M., et al. (2015). Diversity and genetic variation among brevipalpus populations from Brazil and Mexico. PLoS One 10:e0133861. doi: 10.1371/journal.pone.0133861

Sauvetre, P., Veniant, E., Croq, G., Tassi, A. D., Kitajima, E. W., Chabi-Jesus, C., et al. (2018). First report of orchid fleck virus in orchid collection of Jardin du Luxembourg, Paris, France. Plant Dis. 102, 2670-2670. doi: 10.1094/pdis-0218-0371-pdn

Takeda, A., Kaido, M., Okuno, T., and Mise, K. (2004). The C terminus of the movement protein of Brome mosaic virus controls the requirement for coat protein in cell-to-cell movement and plays a role in long-distance movement. J. Gen. Virol. 85, 1751-1761. doi: 10.1099/vir.0.79976-0

Taschner, P. E., Van Der Kuyl, A. C., Neeleman, L., and Bol, J. F. (1991). Replication of an incomplete alfalfa mosaic virus genome in plants transformed with viral replicase genes. Virology 181, 445-450. doi: 10.1016/0042-6822(91)90876-d

Tsai, C. W., Redinbaugh, M. G., Willie, K. J., Reed, S., Goodin, M., and Hogenhout, S. A. (2005). Complete genome sequence and in planta subcellular localization of maize fine streak virus proteins. J. Virol. 79, 5304-5314. doi: 10.1128/jvi.79. 9.5304-5314.2005 van Dun, C. M., Van Vloten-Doting, L., and Bol, J. F. (1988). Expression of alfalfa mosaic virus cDNA1 and 2 in transgenic tobacco plants. Virology 163, 572-578. doi: 10.1016/0042-6822(88)90298-x

Wang, R., and Brattain, M. G. (2007). The maximal size of protein to diffuse through the nuclear pore is larger than $60 \mathrm{kDa}$. FEBS Lett. 581, 3164-3170. doi: 10.1016/j.febslet.2007.05.082

Wolf, S., Deom, C. M., Beachy, R. N., and Lucas, W. J. (1989). Movement protein of tobacco mosaic virus modifies plasmodesmatal size exclusion limit. Science 246, 377-379. doi: 10.1126/science.246.49 28.377

Zamyatnin, A. A., Solovyev, A. G., Bozhkov, P. V., Valkonen, J. P., Morozov, S. Y., and Savenkov, E. I. (2006). Assessment of the integral membrane protein topology in living cells. Plant J. 46, 145-154. doi: 10.1111/j.1365-313x.2006. 02674.x

Zhou, X., Lin, W., Sun, K., Wang, S., Zhou, X., Jackson, A. O., et al. (2019). Specificity of plant rhabdovirus cell-to-cell movement. J. Virol. 93:e00296-19.

Conflict of Interest: The authors declare that the research was conducted in the absence of any commercial or financial relationships that could be construed as a potential conflict of interest.

Copyright (c) 2020 Leastro, Freitas-Astúa, Kitajima, Pallás and Sánchez-Navarro. This is an open-access article distributed under the terms of the Creative Commons Attribution License (CC BY). The use, distribution or reproduction in other forums is permitted, provided the original author(s) and the copyright owner(s) are credited and that the original publication in this journal is cited, in accordance with accepted academic practice. No use, distribution or reproduction is permitted which does not comply with these terms. 